\title{
Plants as Reef Fish: Fitting the Functional Form of Seedling Recruitment
}

\author{
J. R. Poulsen, ${ }^{1, *}$ C. W. Osenberg, ${ }^{1, \uparrow}$ C. J. Clark, ${ }^{1,2, \star}$ D. J. Levey, ${ }^{1, \S}$ and B. M. Bolker ${ }^{1, \|}$
}

1. Department of Zoology, University of Florida, P.O. Box 11852, Gainesville, Florida 32611;

2. School of Natural Resources and Environment, University of Florida, Gainesville, Florida 32611

Submitted April 22, 2006; Accepted February 8, 2007;

Electronically published June 26, 2007

Online enhancements: appendixes.

ABstract: The life histories of many species depend first on dispersal to local sites and then on establishment. After dispersal, density-independent and density-dependent mortalities modify propagule supply, determining the number of individuals that establish. Because multiple factors influence recruitment, the dichotomy of propagule versus establishment limitation is best viewed as a continuum along which the strength of propagule or establishment limitation changes with propagule input. To evaluate the relative importance of seed and establishment limitation for plants, we (1) describe the shape of the recruitment function and (2) use limitation and elasticity analyses to quantify the sensitivity of recruitment to perturbations in seed limitation and density-independent and density-dependent mortality. Using 36 seed augmentation studies for 18 species, we tested four recruitment functions against one another. Although the linear model (accounting for seed limitation and density-independent mortality) fitted the largest number of studies, the nonlinear Beverton-Holt model (accounting for density-dependent mortality) performed better at high densities of seed augmentation. For the 18 species, seed limitation constrained population size more than other sources of limitation at ambient conditions. Seedling density reached saturation with increasing seed density in many studies, but at such high densities that seedling density was primarily limited by seed availability rather than microsite availability or density dependence.

\footnotetext{
* Corresponding author; e-mail: jpoulsen@zoo.ufl.edu.

† E-mail: osenberg@zoo.ufl.edu.

‡ E-mail: cclark@zoo.ufl.edu.

s E-mail: dlevey@zoo.ufl.edu.

" E-mail: bolker@zoo.ufl.edu.
}

Am. Nat. 2007. Vol. 170, pp. 167-183. (c) 2007 by The University of Chicago. 0003-0147/2007/17002-41790\$15.00. All rights reserved.
Keywords: seed limitation, establishment limitation, recruitment function, density dependence, density independence, seedling emergence.

For organisms that are sessile or display high site fidelity, local abundance depends on successful propagule dispersal and establishment (Caley et al. 1996). Most marine and plant populations are open, with dispersal playing a major role in the supply of propagules to local sites. Densityindependent and density-dependent mortalities subsequently modify the initial supply to determine the number of individuals that establish and persist into later life stages. The relative importance of dispersal and establishment processes is uncertain. One perspective holds that population size and distribution of juveniles and adults reflect propagule supply (Gaines and Roughgarden 1985; Eriksson and Ehrlén 1992). A contrasting viewpoint is that distribution and abundance are determined primarily by the quality of suitable sites for recruitment and the effect of density-dependent survival within these sites (Crawley 1990; Hixon and Carr 1997). These processes that limit recruitment are often broadly referred to, respectively, as "seed" and "establishment" limitation in the plant literature and as "supply" and "habitat" limitation in the marine literature. Postdispersal processes can be further partitioned according to whether they cause densitydependent or density-independent mortality between propagule arrival at a site and recruitment into a later life stage (Clark et al. 1998; Schmitt et al. 1999; Muller-Landau et al. 2002; Osenberg et al. 2002).

Any particular system is affected by a combination of dispersal and establishment processes. Thus, most plants, for example, are probably not completely seed or establishment limited. Although several studies have demonstrated the importance of seed and establishment limitation for seedlings (Turnbull et al. 2000; Dalling et al. 2002; Siemann and Rogers 2003), the relative importance of these processes has not been evaluated. The challenge is to quantify both types of limitation, partition the processes into those that are density dependent and those that are density independent, and compare the conditions that in- 
fluence their relative importance as determinants of recruitment. To accomplish this, we need an analytical framework that moves beyond the mere detection of seed or establishment limitation. Such frameworks have been developed in the marine literature (Schmitt et al. 1999; Doherty 2002; Osenberg et al. 2002) but are largely lacking in the plant literature. To quantify the strength of processes that limit recruitment, these approaches first require development of the recruitment function, the functional form that relates the number of recruits (i.e., reef fish or plants) to the initial input of propagules (planktonic larvae or seeds). In this article, we draw on approaches developed for marine fishes to further our understanding of terrestrial plants: first, we develop a conceptual and analytical model of seedling recruitment; second, we use the model to quantify the relative importance of seed and establishment limitation and partition the roles of density-independent and density-dependent processes; third, we apply this framework to 18 plant species, using data from the literature; and finally, we present guidelines on how to most effectively design future experiments to quantify the relative importance of seed and establishment limitation.

\section{Approach}

\section{Conceptual and Analytical Framework}

Most empirical investigations of seed and establishment limitation have experimentally treated these forms of limitation as mutually exclusive processes, despite recognition that they act simultaneously (Muller-Landau et al. 2002). Experiments designed to address what limits plant populations typically involve adding seeds to plots and comparing the number of seedlings to that in control plots where no seeds have been added (Turnbull et al. 2000). If the addition of seeds significantly increases recruitment, then the species is considered to be seed limited. On the other hand, if the addition of seeds has no influence on recruitment, then the species is considered to be establishment limited. In this framework, establishment limitation potentially includes seedling mortality and seed predation as well as seed inviability; once seeds are augmented, any failure to recruit is attributed to postdispersal processes.

We move beyond this dichotomous approach by adopting a framework developed for reef fish (Schmitt et al. 1999; Osenberg et al. 2002). We start by elaborating the recruitment function for plants, which relates the number of recruits (i.e., seedlings or later life stages) to the initial input of seeds. Few attempts have been made to experimentally evaluate plant recruitment functions (but see Shaw and Antonovics 1986), although the relationship between seed density and recruit seedling density has been examined observationally (Harms et al. 2000; HilleRisLambers et al. 2002). Without knowing the recruitment function, we (1) cannot unambiguously estimate seed limitation for any given study, (2) cannot make direct comparisons across species (because of differences in results stemming from experimental protocols, such as level of seed augmentation), and (3) cannot distinguish effects of different processes (e.g., seed and establishment limitation). Knowing the recruitment function facilitates all three of these objectives.

\section{Developing the Recruitment Function}

We take a cohort approach in our evaluation of the functional relationship between seed input and the subsequent density of seedlings. Although any life stage can be used, we focus on seedling emergence because the seedling stage of a plant's life history is thought to be key to establishing that species' distribution and abundance (Augspurger and Kitajima 1992; Levine and Murrell 2003; similar arguments about the early postdispersal stage have been made for reef fish [Doherty 2002]). Specifically, we examine the time between seed arrival at the soil surface and the census of seedlings during approximately the first year of growth (average duration of study $=357$ days, $\mathrm{SD}=244$; app. A in the online edition of the American Naturalist). Establishment limitation is thus determined by factors that constrain the recruitment of new individuals into the seedling population.

The relationship between seed density (i.e., input) and the subsequent density of seedlings (i.e., output or recruitment) can be described by a variety of functions. We now develop a conceptual model of seedling recruitment to demonstrate how the recruitment function can enable us to quantitatively distinguish between seed limitation and establishment limitation. In general, we seek a function that relates recruit density, $R$, to the initial density of seeds, $S$. For illustrative purposes, we use a two-parameter Beverton-Holt (1957) recruitment function,

$$
R=\frac{P_{0} S}{1+\left(P_{0} S / R_{\max }\right)},
$$

where $R$ is the density of recruits (in our case, seedlings) that emerge from an input density of $S$ seeds, $P_{0}$ is the proportion of seeds that recruit in the absence of density effects (i.e., the slope of the recruitment function at $S=0$ ), and $R_{\max }$ is the maximum density of recruits (i.e., $\left.\lim R_{S \rightarrow \infty}=R_{\max }\right)$. Note that equation (1) can be expressed in a continuous-time form, with slightly different meaning of the resulting variables (Osenberg et al. 2002). However, because the studies we draw from have a common end- 
point (recruitment to the seedling stage), we prefer the discrete form.

In seed augmentation experiments, seedlings emerge from the augmented seeds, from the natural seed bank, and from seed rain. Therefore, $R$ can exceed 0 even when seeds have not been added to a plot. Unfortunately, ambient seed density and natural seed rain are rarely reported in the seed limitation literature. Instead, the investigators generally report the number of seeds added to a plot and the resulting number of recruits. Thus,

$$
S=S_{\mathrm{amb}}+A,
$$

where $A$ is the augmentation level (density of added seeds) and $S_{\text {amb }}$ is the ambient (or background) seed density (from the seed bank and seed rain), which defines where the ambient system "sits" on the recruitment function. Given the limitations of existing studies, most of which fail to directly measure seed rain or seed bank, $S_{\text {amb }}$ must be estimated from the recruitment data. Parameters (e.g., $P_{0}$, $R_{\max }$, and $S_{\text {amb }}$ in eqq. [1], [2]) are estimated by fitting models to the data; these estimates then can be used to quantify the relative importance of different processes.

\section{Quantifying Effects of Multiple Processes}

Evaluating the relative importance of seed and establishment limitation (and the roles of density-independent and density-dependent mortalities) can be accomplished by quantifying the sensitivity of recruitment to perturbations in different processes that potentially influence recruitment (e.g., seed limitation, density-independent mortality, and density-dependent mortality). We focus on three general approaches that differ in the size of the perturbation that is imposed. "Limitation" measures how much recruitment increases when a constraint is completely removed, for example, when a site is saturated with seeds or density-independent mortality is absent (Osenberg and Mittelbach 1996; Schmitt et al. 1999). "Sensitivity" quantifies the increase in recruitment for a small absolute change in the parameter (e.g., in seed density), and "elasticity " estimates the proportional increase in recruits, given a very small proportional increase in the parameter (Caswell 2001).

Limitation. We illustrate our approach with the BevertonHolt function and focus on recruit (seedling) density under four scenarios (see fig. 1, table 1; also Schmitt et al. 1999): (1) ambient conditions (described by eq. [1]), which yields $R_{\mathrm{amb}}$, the density of recruits from ambient seed density, and $S_{\text {amb }}$, derived from the seed rain and seed bank; (2) no seed limitation, which yields $R_{\max }$, found by letting $S \rightarrow \infty$ in equation (1) and results from saturating

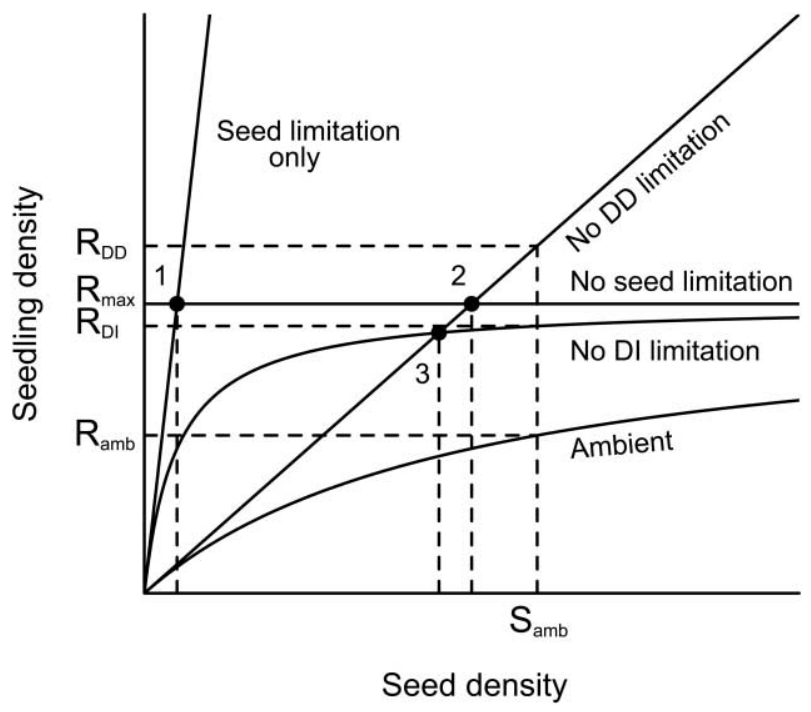

Figure 1: Graphical representation of seed limitation based on the Beverton-Holt (1957) recruitment function (eq. [1]) that relates seedling density (i.e., recruitment, $R$ ) to seed density $(S)$. The "ambient" curve represents an observed relationship between the density of emerged seedlings (i.e., recruits) and initial seed density. When the input of seeds is the only limiting factor, the recruitment function is linear ("Seed limitation only") with a slope of 1 (eq. [1] with $P_{0}=1, R_{\max } \rightarrow \infty$ ), indicating the lack of postdispersal mortality and perfect viability of all seeds. $S_{\text {amb }}$ is the ambient seed density in the system that results from seed rain and the seed bank and yields a seedling density of $R_{\text {amb }}$. Removing limitation due to density-independent mortality $\left(P_{0}=1\right)$ results in a recruit density of $R_{\mathrm{DI}}$ ("No DI limitation"). Therefore, density-independent limitation can be estimated as $L_{\mathrm{DI}}=R_{\mathrm{DI}}-R_{\mathrm{amb}}$. Similarly, removing limitation due to density-dependent mortality $\left(R_{\max } \rightarrow \infty\right)$ results in a seedling density of $R_{\mathrm{DD}}$ ("No DD limitation"). Density-dependent limitation is $L_{\mathrm{DD}}=$ $R_{\mathrm{DD}}-R_{\mathrm{amb}}$. Removing seed limitation $(S \rightarrow \infty)$ results in the saturation density of recruits $\left(R_{\max }\right)$. Seed limitation is the difference between "Ambient" and "No seed limitation" ( $\left.L_{\mathrm{S}}=R_{\max }-R_{\mathrm{amb}}\right)$. Point 1 represents the crossover between $L_{\mathrm{S}}$ and $L_{\mathrm{E}}$ (i.e., where $S=R_{\max }$ ), point 2 represents the crossover between $L_{\mathrm{S}}$ and $L_{\mathrm{DD}}\left(S=R_{\max } / P_{0}\right)$, and point 3 represents the crossover between $L_{\mathrm{DD}}$ and $L_{\mathrm{DI}}\left(S=\left[R_{\max }-P_{0} R_{\max }\right] / P_{0}\right)$. Modified from Schmitt et al. (1999).

the system with seeds; (3) no density-independent limitation, which yields $R_{\mathrm{DI}}$, found by setting $P_{0}=1$ in equation (1); and (4) no density-dependent limitation, which yields $R_{\mathrm{DD}}$, when $R_{\max } \rightarrow \infty$ in equation (1). The amount of limitation imposed by a single process is calculated by subtracting the density of seedlings that occurs under ambient conditions from the density that would occur if the limiting process were removed (fig. 1). Limitation can also be expressed on a relative scale ([$\left(R_{\text {without limitation }}-\right.$ $\left.R_{\mathrm{amb}} / / R_{\mathrm{amb}}\right] \times 100$ ); however, in our empirical analyses, approximately one-third of all the studies resulted in $R_{\mathrm{amb}}=0$, making the relative change undefined (Schmitt et al. 1999). Thus, we focus on absolute limitation in this article. 
Table 1: Limitation (fig. 1), sensitivity, and elasticity for the Beverton-Holt model

\begin{tabular}{lccc}
\hline Parameter perturbed & Limitation $(L)$ & Sensitivity & Elasticity \\
\hline $\begin{array}{l}\text { Seed abundance }(S) \\
\text { Density-independent }\end{array}$ & $L_{\mathrm{S}}=R_{\max }-R_{\mathrm{amb}}$ & $\partial R / \partial S=P_{0} /\left(1+P_{0} S / R_{\max }\right)^{2}$ & $\partial \ln R / \partial \ln S=e_{\mathrm{S}}=1 /\left[1+\left(\mathrm{P}_{0} / R_{\max }\right) S\right]$ \\
$\quad$ mortality $\left(P_{0}\right)$ & $L_{\mathrm{DI}}=R_{\mathrm{DI}}-R_{\mathrm{amb}}$ & $\partial R / \partial P_{0}=S /\left(1+P_{0} S / R_{\max }\right)^{2}$ & $\partial \ln R / \partial \ln P_{0}=e_{P_{0}}=1 /\left[1+\left(P_{0} / R_{\max }\right) S\right]$ \\
$\begin{array}{l}\text { Density dependence } \\
\left(R_{\max }\right)\end{array}$ & $L_{\mathrm{DD}}=R_{\mathrm{DD}}-R_{\mathrm{amb}}$ & $\begin{array}{c}\partial R / \partial R_{\max }=\left(P_{0} S / R_{\max }\right)^{2} /(1+ \\
\left.P_{0} S / R_{\max }\right)^{2}\end{array}$ & $\begin{array}{c}\left.\partial \ln R / \partial \ln R_{\max }=e_{R_{\max }}=\left(P_{0} S / R_{\max }\right) /\left[1+R_{\max }\right)\right] \\
\text { All mortality sources } \\
\left.\quad \text { (i.e., } P_{0} \text { and } R_{\max }\right)\end{array}$ \\
\hline
\end{tabular}

Note: $S=$ seed abundance $=$ seed augmentation, $R=$ density of recruits, $P_{0}=$ density-independent survival, $R_{\max }=$ maximum recruit density (which affects density-dependent survival), DI = density-independent, DD = density-dependent, $\mathrm{E}=$ establishment, and $S_{\text {amb }}=$ background seed density. For our purposes, all functions should be evaluated relative to ambient conditions (limitation) or at ambient conditions (sensitivity and elasticity); thus, $S=S_{\mathrm{amb}}, R_{\mathrm{amb}}=P_{0} S_{\mathrm{amb}} /\left[1+\left(P_{0} / R_{\max }\right) S_{\mathrm{amb}}\right], R_{\mathrm{DI}}=S_{\mathrm{amb}} /\left(1+S_{\mathrm{amb}} / R_{\max }\right)$, and $R_{\mathrm{DD}}=P_{0} S_{\mathrm{amb}}$.

Seed limitation is the difference between the density of recruits that would emerge if the seed supply were limitless and the density of recruits under ambient conditions $\left(L_{\mathrm{S}}=R_{\max }-R_{\mathrm{amb}}\right)$. Note that seed limitation is definable (i.e., not infinite) only if survival is density dependent and recruitment has an upper limit. Assuming a nonlinear recruitment function, the magnitude of seed limitation varies with ambient seed density (fig. 2A). When no seeds naturally arrive in a plot, seed limitation is at its maximum $\left(L_{\mathrm{S}}=R_{\max }\right)$. Seed limitation declines to 0 with increasing ambient seed input (fig. $2 A$ ).

Limitation from density-independent or density-dependent factors can be found by setting $P_{0}=1$ or $R_{\max } \rightarrow$ $\infty$ and comparing these results to recruitment under ambient conditions $\left(R_{\mathrm{amb}}\right)$. Both sources of limitation are lowest at low seed densities $\left(L_{\mathrm{DI}}=0\right.$ and $L_{\mathrm{DD}}=0$ at $S=$ 0 ) and initially increase with increasing seed density (fig. $2 A$ ). However, because density dependence puts a cap on seedling recruitment at high seed inputs, limitation by density-independent mortality $\left(L_{\mathrm{DI}}\right)$ eventually peaks and then declines to 0 (because eliminating density-independent losses has no effect when the system is saturated; line $L_{\mathrm{DI}}$ in fig. $2 A$ ). Limitation by density-dependent mortality $\left(L_{\mathrm{DD}}\right)$ increases monotonically as seed input increases (line $L_{\mathrm{DD}}$ in fig. $2 A$ ).

In our framework, establishment limitation $\left(L_{\mathrm{E}}\right)$ is represented by the removal of both density-independent and density-dependent losses ("Seed limitation only," fig. 1) and can be found by setting $P_{0}=1$ and $R_{\max } \rightarrow \infty$. Thus, $L_{\mathrm{E}}=S-R_{\mathrm{amb}}$. However, because of interactions, establishment limitation cannot be decomposed into an additive function of its two constituents, that is, $L_{\mathrm{E}} \neq L_{\mathrm{DD}}+L_{\mathrm{DI}}$. Removal of establishment limitation ensures that all dispersed seeds survive to recruit $(R=S)$; thus, seed input alone determines local abundance. Establishment limitation increases (and accelerates) with seed density because of the effects of density dependence (fig. 2A).

Establishment limitation is less important than seed lim- itation at low seed densities but becomes more important as seed density increases (fig. $2 A$ ). The crossover between seed and establishment limitation occurs where $L_{\mathrm{S}}=L_{\mathrm{E}}$ or when the number of seeds is equal to the maximum number of recruits (i.e., when $S=R_{\max }$ ). Seed limitation is always greater than or equal to density-independent establishment limitation (fig. 2A). However, the relative importance of seed and density-dependent establishment limitation varies with seed input. Seed limitation exceeds density-dependent establishment limitation until $S=$ $R_{\max } / P_{0}$ (where $L_{\mathrm{S}}=L_{\mathrm{DD}}$ ). At higher seed densities, density-dependent establishment limitation is stronger. The crossover between seed limitation and density-dependent establishment limitation corresponds to a seedling density that is half of the maximum $\left(R=R_{\max } / 2\right)$. Thus, the dominant process is determined by how close the system is to saturation. If $R$ is within $50 \%$ of $R_{\max }$, density-dependent establishment limitation is strongest, and if $R<50 \%$ of $R_{\max }$, seed limitation dominates.

Sensitivity. Sensitivity quantifies the change in recruit density that results from a small change in a parameter (in our case, density-independent survival, $P_{0}$, maximum recruit density, $R_{\max }$, or seed density, $S$ ), that is, $\partial R / \partial x$, where $x$ is the parameter. The qualitative behavior of these three sensitivities is similar to that of the three limitations $\left(L_{\mathrm{DD}}\right.$, $L_{\mathrm{DI}}$, and $L_{\mathrm{S}}$; fig. 2). As seed density increases from $S=$ 0 to $S=\infty, \partial R / \partial S$ declines from $P_{0}$ to $0, \partial R / \partial R_{\max }$ increases from 0 to 1 , and $\partial R / \partial P_{0}$ increases from 0 to an intermediate peak and then decays back to 0 . Note that if every added seed returns a new recruit $(\partial R / \partial S=1)$, then the system is strongly seed limited. If the added seed yields no new recruitment $(\partial R / \partial S=0)$, then the system is not seed limited (i.e., it is establishment limited). However, any real system will be intermediate to these two extremes (note that $\left.0 \leq \partial R / \partial S \leq P_{0}\right)$. Any system with high densityindependent seed mortality $\left(P_{0} \approx 0\right)$ will have small sensitivity to added seeds $(\partial R / \partial S \approx 0)$, even if the system is 
A

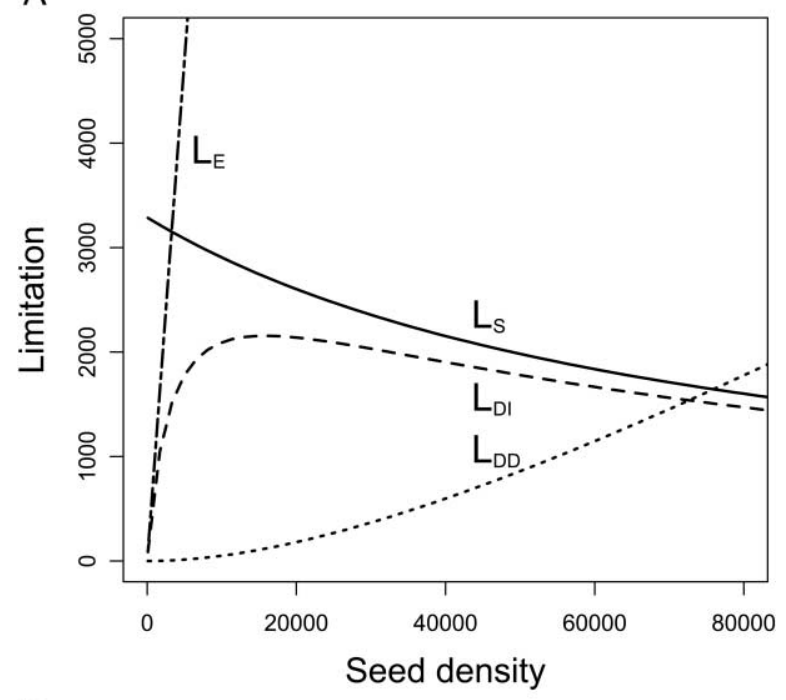

B

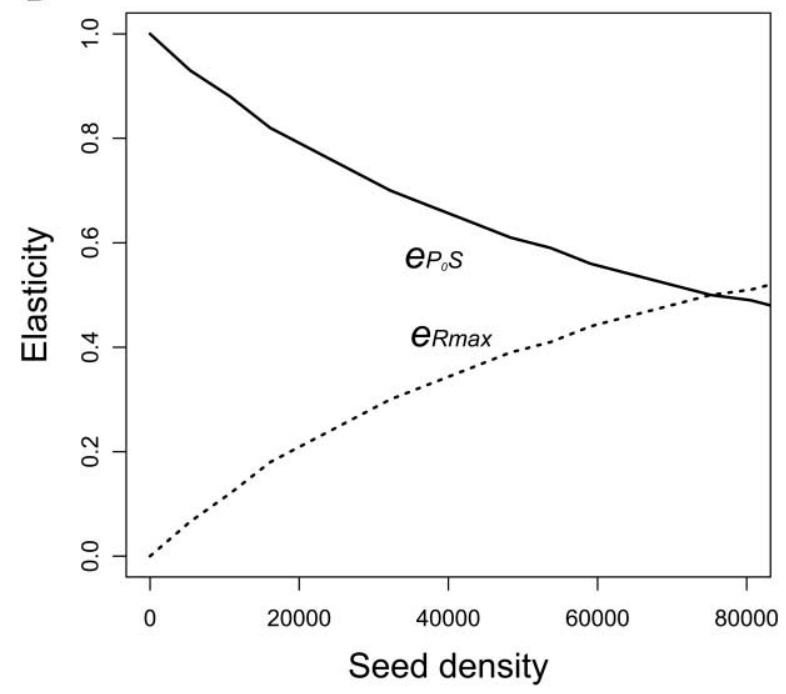

Figure 2: Results of the analyses of limitation $(A)$ and elasticity $(B)$ for Rumex acetosa (Edwards and Crawley 1999) from caged plots in the autumn, where $L_{\mathrm{S}}$ is seed limitation, $L_{\mathrm{DD}}$ is density-dependent limitation, $L_{\mathrm{DI}}$ is density-independent limitation function, $L_{\mathrm{E}}$ is the establishment limitation function, $e_{P_{0} S}$ is the elasticity of seed input $S$ and densityindependent survival $P_{0}$, and $e_{R_{\max }}$ is elasticity of the saturation density $R_{\max }$. A, Seed limitation exceeds density-dependent limitation until $S=R_{\max } / P_{0}$ (where $L_{\mathrm{S}}=L_{\mathrm{DD}}$ ), which occurs at 75,935 seeds $\mathrm{m}^{-2}$ with a recruit density of 1,644 seedlings $\mathrm{m}^{-2}$ (where $R=R_{\max } / 2$ ). At higher seed densities, density-dependent limitation is strongest. The crossover between seed and establishment limitation occurs at 3,284 seeds $\mathrm{m}^{-2} . B$, The relative importances of density-dependent mortality and the combined effects of seed supply and density-independent mortality, as assessed by elasticity, shift as seed input increases, with density-dependent mortality gaining in importance. Seedling density is more sensitive to density-dependent mortality when $S<R_{\max } / P_{0}$ (less than 75,935 seeds $\mathrm{m}^{-2}$ ) and more sensitive to density-dependent mortality when $S>$ $R_{\max } / P_{0}$. Ambient seed densities were estimated to be 93 seeds $\mathrm{m}^{-2}$ (table 2 ), indicating that this system is primarily seed limited. far from being saturated with recruits $\left(R_{\mathrm{amb}} \ll R_{\max }\right)$, and it is therefore strongly seed limited, as measured by $L_{\mathrm{S}}$.

To deal with these intermediate cases (such as $\partial R / \partial S \approx 0$, but $R_{\mathrm{amb}} \ll R_{\max }$ ), it would be helpful to compare the relative strength of different sensitivities rather than focus on the magnitude of a single value. Unfortunately, sensitivities are difficult to compare because they may have different units (e.g., $\partial R / \partial P_{0}$ is the change in recruits per small change in proportion surviving, whereas $\partial R / \partial S$ is the change in recruits per seed). Because sensitivities compare responses on dissimilar scales, this approach has fallen out of favor in much of ecology (e.g., Caswell 2001). We therefore do not evaluate sensitivities further but instead discuss the use of elasticities (in which all parameters are compared on a proportionate basis). We return to the issue of sensitivity in "Discussion," in light of a companion analysis (Clark et al. 2007).

Elasticity. Elasticity, $e$, quantifies the proportional change in recruit density that results from a small proportional change in model parameters (in our case, $P_{0}, R_{\max }$, and $\left.S_{\text {amb }}\right)$; that is, $e_{x}=\partial \ln R / \partial \ln x=(\partial R / R) /(\partial x / x)$, where $x$ is a parameter in the model. For example, $e_{\mathrm{S}}=1$ indicates that a small proportional change in seed input, $S$, yields an equivalent proportional change in seedling density, $R$; $e_{\mathrm{S}}<1$ indicates that there is a less than proportional change in seedling density, and $e_{\mathrm{S}}>1$ indicates a greater than proportional change. Note that because $P_{0}$ and $S$ always appear together in the Beverton-Holt model, their elasticities are equal. We therefore examine their joint elasticity (i.e., $e_{S}=e_{P_{0}}=e_{P_{0} S}$ ).

Elasticities of the Beverton-Holt parameters vary between 0 and 1 , indicating that increased seed arrival or survival (due to relaxation of density-independent and density-dependent mortalities) leads to increases in the numbers of emerged seedlings that are proportionally smaller than the proportional change in the model parameters (table 1; fig. $2 B$ ). The elasticities of $P_{0}$ and $R_{\max }$ are inversely related: $e_{P_{0} S}$ decreases as $e_{R_{\max }}$ increases because $e_{P_{0} S}+e_{R_{\max }}=1$. Thus, as with limitation, the relative importance of density-dependent processes and the combined effects of seed supply and density-independent mortality shift as seed density increases, with density-dependent mortality gaining in importance (fig. $2 B$ ). This shift occurs at the same point as in the limitation analysis (Schmitt et al. 1999): seedling density is more elastic to density-independent mortality when $S<R_{\max } / P_{0}$ and more elastic to density-dependent mortality when $S>R_{\max } / P_{0}$.

The above discussion illustrates how limitation and elasticity, in combination with the recruitment function, can be used to quantify the relative importance of different processes, such as seed supply and microsite quality, and how these effects depend on seed input. We next turn to 
empirical studies to apply our conceptual framework and to examine the relative importance of seed limitation and density-independent and density-dependent mortalities for the seed augmentation studies to which this approach can be applied.

\section{Methods}

\section{Database: Search Methods and Study Selection}

We searched the literature for published articles in which seeds were experimentally added to plots (see Clark et al. 2007 for details of the literature search). We found nine publications describing 37 experiments in which seeds of 18 different species had been sown at four or more densities (app. A). A large number of additional studies were found in which seeds were sown at only two densities (none and augmented), and three studies used three densities; these were not used in our analyses because we could not estimate a nonlinear recruitment function with error with fewer than four densities. We defined a study as a single experiment when a species was augmented at four or more densities under the same environmental context (e.g., habitat type, season, or disturbance). For cases in which multiple density treatments were crossed with two or more treatments (e.g., caged vs. uncaged), we considered these to constitute two or more studies.

\section{Analytical Procedure}

Application of the conceptual framework required several steps. Briefly, the first step involved identification of candidate models of recruitment that include the biological processes of interest (seed limitation, density independence, and density dependence). Second, the models were tested against each other, and parameter values and measures of variation were estimated. Because of the small sample for each study, we did not fit parameters and error structure separately to each data set. Instead, we used a Box-Cox transformation to homogenize the variance of all studies and then estimated parameters for each study (see "Data Modification and Transformation"). Third, we averaged estimates for each parameter across studies, using a random-effects meta-analysis (Gurevitch and Hedges 1999). Finally, using these parameter estimates, we calculated limitation and elasticity to evaluate the relative importance of seed and establishment limitation (and the roles of density-independent and density-dependent mortalities). We now describe each of these steps in detail.

\section{Step 1: Finding the Recruitment Function}

In preliminary analyses, we first compared the curvilinear power function $\left(R=a S^{b}\right.$, where $a$ and $b$ are fitted constants) and the hump-shaped Ricker function $(R=$ $a S e^{-b S}$ ) against the asymptotic Beverton-Holt function (eq. [1]) to determine the most appropriate nonlinear recruitment function. The Beverton-Holt performed better than the other two models for seedling recruitment, so we report only results using the Beverton-Holt function. Because the Beverton-Holt simplifies to a linear function (as $R_{\max } \rightarrow \infty$ ), fitting of the Beverton-Holt function provides a direct discrimination between linear and nonlinear functions.

To determine the best model of seedling recruitment (fig. 1), we used a nested model approach based on the Beverton-Holt function (eqq. [1], [2]) to examine the fit of the seed augmentation data to four models: first, seed limitation only (i.e., no density-independent or densitydependent mortality; setting $P_{0}=1$ and $R_{\max } \rightarrow \infty$ and estimating $S_{\mathrm{amb}}$ ):

$$
R=A+S_{\mathrm{amb}}
$$

second, no density-dependent limitation (letting $R_{\max } \rightarrow$ $\infty$ and estimating $P_{0}$ and $\left.S_{\mathrm{amb}}\right)$ :

$$
R=P_{0}\left(A+S_{\mathrm{amb}}\right)
$$

third, no density-independent limitation (setting $P_{0}=1$, and estimating $R_{\max }$ and $S_{\mathrm{amb}}$ ):

$$
R=\frac{A+S_{\mathrm{amb}}}{1+\left[\left(A+S_{\mathrm{amb}}\right) / R_{\mathrm{max}}\right]}
$$

fourth, seed limitation and density-independent and density-dependent limitation (estimating $P_{0}, R_{\max }$, and $S_{\mathrm{amb}}$, i.e., the full Beverton-Holt model):

$$
R=\frac{P_{0}\left(A+S_{\mathrm{amb}}\right)}{1+\left\{\left[P_{0}\left(A+S_{\mathrm{amb}}\right)\right] / R_{\max }\right\}}
$$

The models had one (eq. [3]), two (eqq. [4], [5]), or three (eq. [6]) parameters.

\section{Step 2: Model Fitting and Comparison}

Data Modification and Transformation. From each study, we extracted the number (or density) of seeds added at each augmentation level and the number (or density) of seedlings that subsequently emerged in plots. Many studies reported the density of seeds and seedlings within a plot. Because the data were originally collected as counts of 
seedlings, we converted densities to counts where necessary. Although it would be preferable to use the raw data (each of the replicates for a single augmentation level) for model fitting, most of the studies presented only a mean per augmentation level. Therefore, the sample sizes of the empirical studies used here are derived from a single point for each augmentation level and limited to four to nine augmentation levels. Because of the small sample size of most of the empirical studies, our power to detect nonlinear recruitment functions is limited; we return to this issue in "Results."

We also determined the relationship between the mean and the variance of the data, which we used to guide data transformations. We fitted a Box-Cox transformation (Venables and Ripley 2002), $f(y)=\left(y^{\lambda}-1\right) / \lambda$, using the most complex model (i.e., eq. [6]) and combining the residuals from all of the data sets. The estimated value of $\lambda$ was $0.22(95 \%$ confidence interval $[\mathrm{CI}]=0.16-0.27)$, halfway between $\lambda=0$ (corresponding to a $\log$ transformation) and $\lambda=0.5$ (square root transformation, which is appropriate for Poisson-distributed data). The variance scaling implied by this transformation (variance $\approx$ mean $^{1.5}$ ) approximates (but is not identical to) a negative binomial distribution, where the variance scales with the mean for small values and with the mean squared for large values.

Fitting Models to Data. Using the Box-Cox transformation (with $\lambda=0.22$ ) to homogenize the variance (transforming the predicted values as well as the data to keep the functional forms of the models the same), we then fitted the four models of seedling recruitment (eqq. [3]-[6]) to the data for each of the seed augmentation studies, minimizing the sums of squares. Because very few data points were available for each individual fit (four to nine values with which to estimate models with one to three parameters), fitting the models separately for each species would have led to very uncertain estimates of the residual variance-in many cases estimates based on a single residual degree of freedom. Thus, we estimated the residual variance (needed to estimate confidence limits and test between models) from the combined residuals of all of the data sets. From the combined residual sums of squares, we calculated the negative log likelihood as

$$
\mathrm{NLL}_{i}=C+\left(\mathrm{df}_{i} / 2\right) \log \left(\mathrm{RSS}_{i} / \mathrm{df}_{i}\right),
$$

where $\mathrm{NLL}_{i}$ is the negative log likelihood for model $i, C$ is a constant that does not depend on the model, and $\mathrm{df}_{i}$ and RSS $i$ are the degrees of freedom and residual sums of squares, respectively, for model $i$. We then used the likelihood ratio test to compare fits of the models. Specifically, we compared a negative log likelihood based on the com- bined residual sums of squares $(\mathrm{df}=64)$ for all studies fitted with the more complex model (i.e., eq. [6]) to one based on the combined sums of squares when a single focal study was fitted with a reduced, less complex model (i.e., eq. [3], [4], or [5]), with all the rest of the species still fitted with the more complex model. This procedure isolated the difference in goodness of fit caused by fitting a reduced model for a particular study while still allowing reasonably reliable estimates of residual variance.

\section{Step 3: Estimating Average Parameter Values}

To evaluate the average parameter values and their heterogeneity across studies, we conducted a random-effects meta-analysis for each of the model parameters: $P_{0}, R_{\max }$, and $S_{\text {amb }}$. Meta-analysis combines effect sizes obtained from a collection of studies, giving greater weight to studies with more precise parameter estimates (Gurevitch and Hedges 1999). Meta-analysis requires an estimate of the parameter and a standard error of the estimate (Osenberg et al. 1999). Symmetric standard errors were calculated for each parameter during the model fitting. The estimates and standard errors of $P_{0}, R_{\max }$, and $S_{\text {amb }}$ for each study were used to calculate the weighted-average effect size (i.e., $\bar{R}_{\max }, \bar{P}_{0}$, or $\bar{S}_{\text {amb }}$ ) and bias-corrected $95 \%$ CIs of each parameter using resampling methods with 10,000 iterations in MetaWin 2.0 (Rosenberg et al. 2000). We examined the heterogeneity of effect sizes with $\varrho$ statistics (Hedges and Olkin 1985), which are analogous to weighted sums of squares that follow a $\chi^{2}$ distribution. The corresponding $P$ value indicates whether the variance among parameter estimates from different studies is greater than would be expected from the within-study (sampling) error.

\section{Step 4: Evaluation of Limitation and Elasticity}

We estimated limitation and elasticity, using the parameter estimates obtained from the Beverton-Holt model and the formulas given in table 1 . With the exception of the metaanalysis, all modeling and statistical procedures were performed using the R Language, version 2.2.1 (R Development Core Team 2005).

\section{Results}

\section{Recruitment Function}

We fitted the four models (eqq. [3]-[6]) to all 37 data sets, with the exception of Saxifraga tridactilytes which could not be fitted by the no-density-dependence model (i.e., eq. [4], estimating $P_{0}$, and $S_{\text {amb }}$ ). Visual examination of the Saxifraga data suggested a negative slope to the recruitment function. This study was therefore excluded 
from the comparison of models of seedling recruitment (and may represent a rare case where the Ricker function might be a better descriptor of the recruitment function).

Seed limitation, density-independent mortality, and/or density-dependent mortality were important for describing seedling recruitment (table 2; fig. 3 ). The simplest model, seed limitation only (i.e., eq. [3], estimating only $S_{\text {amb }}$ ), failed to fit any of the 36 studies. The no-densitydependence model (i.e., eq. [4], estimating $P_{0}$ and $S_{\mathrm{amb}}$ and thus accounting for density-independent mortality and seed limitation) best described the data in 22 cases. The no-density-independence model (i.e., eq. [5], estimating $R_{\max }$ and $S_{\text {amb }}$ and thus accounting for density-dependent mortality and seed limitation) best described the data in 10 cases. The full model-seed limitation, density independence, and density dependence (i.e., fitting $P_{0}, R_{\max }$, and $S_{\mathrm{amb}}$ )—was better than the other models in four cases. Thus, nearly $40 \%$ of all studies were best fitted by a curvilinear recruitment function that incorporated densitydependent mortality. Sixty percent of studies were best fitted by a linear function, although density-independent mortality was an important factor (i.e., CIs on $P_{0}$ excluded 1) in $79 \%$ of studies. Because of the small number of augmentation levels, our power to detect nonlinear recruitment functions was limited. Thus, these results should be interpreted cautiously because significance tests of species-specific parameters are based on few data points and are therefore likely to underestimate the number of species for which a nonlinear function best describes the data.

\section{Average Parameter Values: Overall Effect of Density Independence and Density Dependence}

Here we examine the overall effects of density-independent and density-dependent survival across the 37 studies, using the parameter estimates from the full Beverton-Holt model (i.e., estimating $P_{0}, R_{\max }$, and $S_{\text {amb }}$ ). We use all studies in this summary (not just "significant" ones or ones with particular values of parameters), but in eight of them, $R_{\max }$ was estimated as infinite (because those studies used seed densities well below saturation and therefore $R_{\max }$ could not be adequately estimated). We also use the full model because it is more general, includes the linear model as a special case, and can yield better combined estimates of parameters (e.g., $R_{\max }$ ) that might be hard to estimate in any given study. Our approach downweights uncertain estimates and therefore discounts less informative studies.

The mean (weighted) density-independent survivorship rate $\left(\bar{P}_{0}=0.022,95 \% \mathrm{CI}=0.010-0.056, n=37\right)$, indicated that only $2.2 \%$ of all augmented seeds typically survive to the seedling stage in the absence of density-dependent losses. The density-independent sur- vival rate did not vary significantly among studies $\left(Q_{i}=36.75\right.$, df $\left.=36, P=.434\right)$. The average maximum seedling density, $\bar{R}_{\max }$, was $1.46 \times 10^{5}$ seedlings $\mathrm{m}^{-2}\left(95 \% \mathrm{CI}=\left[3.92 \times 10^{3}\right]-\left[5.48 \times 10^{5}\right], n=29\right)$ and exhibited significant heterogeneity among studies $\left(Q=7.67 \times 10^{3}, \quad \mathrm{df}=28, \quad P<.001\right)$. Average background seed rain, $\bar{S}_{\mathrm{amb}}$, was $1.96 \times 10^{3}$ seedlings $\mathrm{m}^{-2}$ $\left(95 \% \mathrm{CI}=688-\left[3.910 \times 10^{3}\right], n=37\right)$ and also varied significantly among studies $\left(Q=5.66 \times 10^{3}\right.$, df $=36$, $P<.001)$.

Using the best models for each study, parameter estimates for $P_{0}, R_{\max }$, and $S_{\text {amb }}$ did not differ significantly among the different forms of the model. For example, the parameter reflecting density dependence $\left(R_{\max }\right)$ in the nodensity-independence model (fitting $R_{\max }$ and $S_{\mathrm{amb}}$ ), was not significantly different from the estimate obtained from the full model $\left(\bar{R}_{\text {max }}=639.15, n=10,95 \% \mathrm{CI}=\right.$ $119.13-2,819.20$ vs. $\bar{R}_{\max }=82.14, n=4,95 \%$ CI $=$ 0.23-199.80). Similarly, density-independent survival did not differ between the no-density-dependence model $\left(\bar{P}_{0}=0.027, n=22,95 \% \mathrm{CI}=0.012-0.064\right)$ and the full model $\left(\bar{P}_{0}=0.023, n=4,95 \% \mathrm{CI}=0.015-0.041\right)$. The estimate of background seed rain also did not significantly differ among the models (no density dependence: $\bar{S}_{\mathrm{amb}}=4,141, n=22,95 \% \mathrm{CI}=1,428-8,285$; no density independence: $\bar{S}_{\mathrm{amb}}=980, n=10,95 \%$ CI $=0-3,767$; seed limitation, density independence, and density dependence: $\left.\bar{S}_{\mathrm{amb}}=1,424, n=4,95 \% \mathrm{CI}=856-2,631\right)$.

Model fits to the data largely depended on the maximum density of seed augmentation, which determined whether the curve reached an asymptote. Of the 14 studies fitted best by a curvilinear model (i.e., with $R_{\max }$ fitted), 13 (93\%) had maximum seed augmentation densities of 200,000 seeds $\mathrm{m}^{-2}$. By contrast, only five $(23 \%)$ of the studies best fitted by the linear function had maximum seed augmentation densities of 200,000 seeds $\mathrm{m}^{-2}$, and most had maximum seed densities of less than 20,000 seeds $\mathrm{m}^{-2}$.

\section{Patterns of Limitation}

Having shown that the Beverton-Holt is a plausible general model for seedling recruitment, especially under relatively high seed augmentation densities, when the asymptote is best revealed, we now examine the relative importance of each of the three processes (seed limitation, density independence, and density dependence) for the 36 studies. In general, at ambient conditions, seed limitation constrained recruitment more than either density-independent or density-dependent limitation: $L_{\mathrm{S}}$ exceeded both $L_{\mathrm{DD}}$ and $L_{\mathrm{DI}}$ in 33 of 36 cases. Of course, mathematically, seed limitation must always be greater than or equal to density-independent limitation (see "Limitation"). However, these results demonstrate a relatively minor role for 
Table 2: Comparison of models for all studies using the likelihood ratio test

\begin{tabular}{|c|c|c|c|c|c|c|c|}
\hline \multirow[b]{2}{*}{ Species (code), treatment } & \multirow{2}{*}{$\begin{array}{c}\begin{array}{c}\text { Seed } \\
\text { limitation } \\
\text { only }^{\mathrm{a}}\end{array} \\
\text { NLL }\end{array}$} & \multicolumn{2}{|c|}{$\begin{array}{l}\text { No density- } \\
\text { dependent } \\
\text { limitation }^{\text {b }}\end{array}$} & \multicolumn{2}{|c|}{$\begin{array}{l}\text { No density- } \\
\text { independent } \\
\text { limitation }^{c}\end{array}$} & \multicolumn{2}{|c|}{ Full model $^{\mathrm{d}}$} \\
\hline & & NLL & $P$ & NLL & $P$ & NLL & $P$ \\
\hline$\overline{\text { Aphanes arvensis (APHAR) }}$ & 73.92 & 29.37 & $<.0001$ & 31.15 & $<.0001$ & 29.09 & .451 \\
\hline Arenaria serpyllifolia (ARESE) & 89.74 & 29.06 & $<.0001$ & 29.24 & $<.0001$ & 29.09 & 1 \\
\hline \multicolumn{8}{|l|}{ Arrhenatherum elatius (ARREL): } \\
\hline Spring & 155.10 & 33.25 & $<.0001$ & 29.28 & $<.0001$ & 29.09 & .5382 \\
\hline Spring + caged & 155.23 & 34.98 & $<.0001$ & 29.16 & $<.0001$ & 29.09 & .6951 \\
\hline Autumn & 152.69 & 29.14 & $<.0001$ & 36.20 & $<.0001$ & 29.09 & .7464 \\
\hline Autumn + caged & 150.20 & 34.35 & $<.0001$ & 31.41 & $<.0001$ & 29.09 & .031 \\
\hline \multicolumn{8}{|l|}{ Balsamorhiza sagittata (BALSA): } \\
\hline Elevation $1,525 \mathrm{~m}$ & 58.12 & 29.05 & $<.0001$ & 29.06 & $<.0001$ & 29.09 & 1 \\
\hline Elevation $1,825 \mathrm{~m}$ & 59.90 & 29.06 & $<.0001$ & 29.54 & $<.0001$ & 29.09 & 1 \\
\hline \multicolumn{8}{|l|}{ Cakile edentula (CAKED): } \\
\hline Seaward & 34.53 & 29.06 & .0009 & 31.68 & .017 & 29.09 & 1 \\
\hline Landward & 34.60 & 29.06 & .0009 & 32.29 & .0314 & 29.09 & 1 \\
\hline Midbeach & 48.32 & 29.23 & $<.0001$ & 31.46 & $<.0001$ & 29.09 & .5911 \\
\hline Ammonium nitrate & 53.40 & 29.20 & $<.0001$ & 32.74 & $<.0001$ & 29.09 & .6303 \\
\hline \multicolumn{8}{|l|}{ Centaurea nigra (CENNI): } \\
\hline Spring & 156.03 & 34.11 & $<.0001$ & 29.16 & $<.0001$ & 29.09 & .7091 \\
\hline Spring + caged & 154.83 & 34.78 & $<.0001$ & 29.15 & $<.0001$ & 29.09 & .7265 \\
\hline Autumn & 148.75 & 29.78 & $<.0001$ & 35.54 & $<.0001$ & 29.09 & .2405 \\
\hline Autumn + caged & 147.23 & 35.63 & $<.0001$ & 31.57 & $<.0001$ & 29.09 & .0258 \\
\hline Cerastium diffusum (CERDI) & 83.00 & 29.38 & $<.0001$ & 29.06 & $<.0001$ & 29.09 & 1 \\
\hline Cerastium glomeratum (CERGL) & 96.89 & 29.15 & $<.0001$ & 29.20 & $<.0001$ & 29.09 & .7248 \\
\hline \multicolumn{8}{|l|}{ Festuca rubra (FESRU): } \\
\hline Spring & 155.41 & 33.60 & $<.0001$ & 29.14 & $<.0001$ & 29.09 & .7542 \\
\hline Spring + caged & 154.86 & 35.17 & $<.0001$ & 29.25 & $<.0001$ & 29.09 & .5735 \\
\hline Autumn & 151.21 & 29.18 & $<.0001$ & 37.73 & $<.0001$ & 29.09 & .6705 \\
\hline Autumn + caged & 148.67 & 34.57 & $<.0001$ & 31.92 & $<.0001$ & 29.09 & .0174 \\
\hline \multicolumn{8}{|l|}{ Floerkea proserpinacoides (FLOPR): } \\
\hline Site 1 & 36.77 & 29.06 & .0001 & 31.62 & .0013 & 29.09 & 1 \\
\hline Site 2 & 31.94 & 29.06 & .0164 & 30.62 & .1043 & 29.09 & 1 \\
\hline Lathyrus vernus (LATVE) & 92.06 & 29.06 & $<.0001$ & 52.51 & $<.0001$ & 29.09 & 1 \\
\hline Myosotis ramosissima (MYORA) & 79.15 & 29.06 & $<.0001$ & 31.22 & $<.0001$ & 29.09 & 1 \\
\hline \multicolumn{8}{|l|}{ Plantago coronopus (PLACO): } \\
\hline Vegetation removed & 64.24 & 29.53 & $<.0001$ & 30.56 & $<.0001$ & 29.09 & .3482 \\
\hline None & 87.84 & 30.61 & $<.0001$ & 29.21 & $<.0001$ & 29.09 & .618 \\
\hline \multicolumn{8}{|l|}{ Rumex acetosa (RUMAC): } \\
\hline Spring & 154.79 & 35.49 & $<.0001$ & 29.19 & $<.0001$ & 29.09 & .6434 \\
\hline Spring + caged & 155.28 & 35.72 & $<.0001$ & 29.06 & $<.0001$ & 29.09 & 1 \\
\hline Autumn & 146.34 & 29.10 & $<.0001$ & 43.71 & $<.0001$ & 29.09 & .8595 \\
\hline Autumn + caged & 142.36 & 37.63 & $<.0001$ & 34.32 & $<.0001$ & 29.09 & .0012 \\
\hline Salvia lyrata (SALLY) & 79.22 & 29.06 & $<.0001$ & 45.49 & $<.0001$ & 29.09 & 1 \\
\hline Veronica arvensis (VERAR) & 80.88 & 29.06 & $<.0001$ & 30.52 & $<.0001$ & 29.09 & 1 \\
\hline \multicolumn{8}{|l|}{ Viola semptemloba (VIOSE): } \\
\hline Road & 35.19 & 29.12 & .0005 & 29.56 & .0008 & 29.09 & .7998 \\
\hline Sink & 38.91 & 29.09 & $<.0001$ & 30.00 & $<.0001$ & 29.09 & .9144 \\
\hline
\end{tabular}

Note: NLL $=$ negative log likelihood. The same species may appear in multiple studies because some species were subjected to different treatments (i.e., differences in habitat or season or imposed treatments, such as caging of seeds, addition of fertilizer, or disturbance of the ground). The two-parameter models (fitting either $P_{0}$ and $S_{\text {amb }}$ or $R_{\max }$ and $S_{\text {amb }}$ ) were first compared against the one-parameter $S_{\text {amb }}$ model (fitting $S_{\text {amb }}$; $\mathrm{df}=63$ ). The best two-parameter model (with the lowest NLL) was then compared to the full model ( $\mathrm{df}=62$ ). Based on the lowest NLL score (in boldface), the no-density-dependence model won 22 times, the no-density-independence model won 10 times, and the full model (seed limitation, density-independent limitation, and density-dependent limitation) won four times. The seed-limitationonly model never won against the other models.

${ }^{\text {a }}$ Fitting $S_{\text {amb }}\left(P_{0}=1 ; R_{\max } \rightarrow \infty\right)$.

${ }^{\mathrm{b}}$ Fitting $P_{0}$ and $S_{\text {amb }}\left(R_{\max } \rightarrow \infty\right)$.

${ }^{c}$ Fitting $R_{\max }$ and $S_{\text {amb }}\left(P_{0}=1\right)$.

d Seed, density-independent, and density-dependent limitation; fitting $P_{0}, R_{\max }$, and $S_{\text {amb }}$. 
density dependence: density-dependent limitation was greater than seed limitation in only three studies (table 3 ). Even in the 14 cases in which there was demonstrable density dependence, seed limitation exceeded densitydependent limitation in 13 cases. Establishment limitation (the aggregate effect of density-dependent and densityindependent mortalities) was greater than seed limitation for only four of 36 studies. If we restrict our attention to the 14 studies with demonstrable density dependence, average seed limitation was 2,787 seedlings $\mathrm{m}^{-2}$ ( $\mathrm{SD}=$ $8,301)$, meaning that complete saturation of the plot with seeds would result in the addition of approximately 3,000 seedlings $\mathrm{m}^{-2}$. Density-independent limitation was 292 seedlings $\mathrm{m}^{-2}(\mathrm{SD}=1,014)$, and average density-dependent limitation was 148 seedlings $\mathrm{m}^{-2}(\mathrm{SD}=481)$. Thus, even for the studies in which there was the greatest evidence of density-dependent recruitment, seed limitation was an order of magnitude greater than limitation imposed by density-dependent or density-independent losses.

\section{Elasticities: Where Do Systems Sit on the Recruitment Function?}

The above results suggest that systems rarely have sufficient seed input to incur strong density dependence. However, it is difficult to make quantitative comparisons among systems because of large differences in maximum recruit density (e.g., comparing grasses with trees). Alternatively, relative patterns of limitation can be evaluated by determining where plant systems are located along the recruitment function: for example, by comparing recruitment at ambient seed density $\left(R_{\mathrm{amb}}\right)$ to the maximum possible recruitment $\left(R_{\max }\right)$. For the Beverton-Holt function, elasticity of the density dependence parameter provides a direct measure of how far a system sits along the recruitment function (i.e., how close the system is to saturation): $e_{R_{\max }}=R_{\mathrm{amb}} / R_{\max }$. This measure of saturation ranges from 0 (near the base of the recruitment function) to 1 (on the asymptote of the function). On average, systems were only $6 \%$ saturated $\left(\bar{e}_{R_{\max }}=0.06, \mathrm{SD}=0.18\right)$. Thirty-three of the 36 studies were located closer to the base of the recruitment function than to the asymptote (i.e., $e_{R_{\max }}<$ $0.5)$, while only three studies approached saturation $\left(e_{R_{\max }} \geq 0.5\right.$; table 3$)$, indicating that density-dependent mortality only rarely plays a predominant role. Even the 14 studies with demonstrable density dependence sat close to the base of the recruitment function $\left(\bar{e}_{R_{\max }}=0.04\right.$, $\mathrm{SD}=0.15)$; only one of the 14 had $\left.e_{R_{\max }} \geq 0.5\right)$.

\section{Discussion \\ Recruitment Function}

For the majority of the studies we examined, the linear function accounting for seed limitation and densityindependent mortality was the best model of seed-toseedling recruitment. However, the nonlinear BevertonHolt function, which contains an additional parameter describing the maximum density of recruits (and accounts for density-dependent mortality), best described the seedling recruitment function in $40 \%$ of the studies. Because the Beverton-Holt function reduces to the linear model under particular conditions (as $R_{\max } \rightarrow \infty$ ), it is able to deal with both linear and nonlinear relationships.

Three lines of evidence suggest that a nonlinear function accounting for density-dependent mortality may be an even more widely applicable model of seedling recruitment than suggested by our analyses. First, because of the small sample size for most of the empirical studies (four to nine augmentation levels), there was limited power to detect anything but strong density dependence. Second, densitydependent mortality by seed predators and pathogens has been shown to reduce seedling emergence in both tropical and temperate regions (Janzen 1970; Webb and Peart 1999; Harms et al. 2000; Packer and Clay 2000; HilleRisLambers et al. 2002). Therefore, a functional form that does not take into account the density-dependent processes that influence recruitment is of limited general use. Third, most study systems were far from saturation under ambient seed rain, making it challenging to detect nonlinearity unless augmentation was very high. Indeed, the studies with the highest densities of seed augmentation tended to be best fitted with the asymptotic Beverton-Holt function, suggesting that the other cases may have favored the linear function because seed input did not approach the level necessary to detect saturation (see also Osenberg et al. 2002).

\section{Relative Influence of Seed and Establishment Limitation on Seedling Recruitment}

Our results indicate that under ambient conditions, removal of density-dependent and density-independent sources of mortality increases seedling recruitment only slightly, because of the low ambient seed input in these systems; that is, removing these mortality sources had little effect because there were few seeds to act on. Instead, seed supply placed a greater constraint on local abundance of most populations. Therefore, saturating experimental plots with seeds typically resulted in a greater density of emerged seedlings than did removing mortality factors.

In a meta-analysis of 159 species, Clark et al. (2007) found that a small proportion of seeds added to plots 

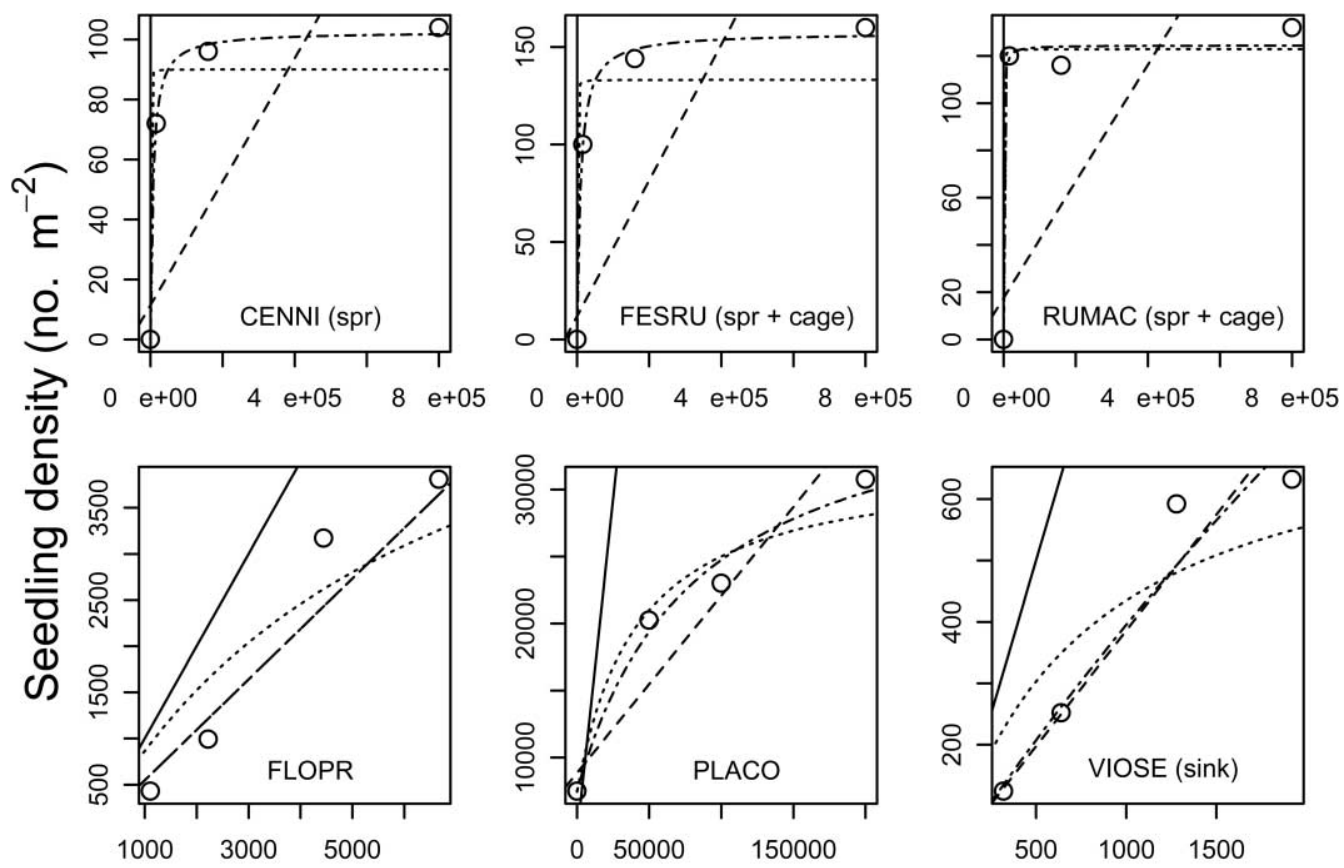

Seed density (no. $\mathrm{m}^{-2}$ )

Figure 3: Fit of four candidate recruitment function models to seed augmentation data (density of seedlings per square meter vs. density of seeds added to a plot) for six of the 37 studies. The solid line represents the seed-limitation-only model (fitting $S_{\text {amb }}$ ), the dashed line represents the nodensity-dependent-limitation model (fitting $P_{0}$ and $S_{\text {amb }}$ ), the dotted line represents the no-density-independent-limitation model (fitting $R_{\max }$ and $S_{\text {amb }}$ ), and the dash-dotted line represents the seed-limitation, density-independent-limitation, and density-dependent-limitation model (fitting $P_{0}$, $R_{\max }$, and $\left.S_{\mathrm{amb}}\right)$. Codes at the bottom of the plots are the first two letters of the genus name and first three letters of the species name, with the type of disturbance abbreviated in parentheses. See table 2 for a full description of the species name and disturbance and/or treatment. Appendix $\mathrm{B}$, in the online edition of the American Naturalist, includes plots of the data and fitted models for all 37 studies.

actually recruit $(\sim 15 \%)$ and concluded that postdispersal mortality (all possible processes contributing to establishment limitation) is the dominant constraint on local abundance. Our results, using a smaller number of studies with more augmentation levels, gave similar results: under low levels of ambient seed density, survival to seedlings was very low (on the order of $1 \%-6 \%$ ). Clark et al.'s metaanalysis used a large number of seed augmentation studies that included only one augmentation level. Thus, they were not able to parameterize a recruitment function. Instead, they quantified the per seed recruitment response (e.g., comparable to approximating sensitivity, $\partial R / \partial S$, if seed augmentation were small relative to the degree of nonlinearity in the recruitment function) and used this to assess seed limitation. In contrast to our results, they concluded that populations were not strongly seed limited. The apparent disparity of findings between these two studies is due to the difference in how we defined seed limitation (see above discussion of sensitivity). Armed with Clark et al.'s extensive analysis of the per seed response of plants to seed augmentation and our knowledge of the recruit- ment function, we can offer a synthesis of the findings of these two articles. Few seed augmentation studies result in saturation, and most systems lie near the base of the recruitment function. However, density-independent mortality losses are large $(>85 \%)$, so that even at low seed densities, few seeds recruit. Consequently, adding a few new seeds results in very few recruits (losses are high). Removing all mortality sources will increase recruitment only slightly because ambient seed density is so low. Instead, because the system is far from saturation, adding large numbers of seeds to the system will lead to a large increase in seedlings even though most of the seeds will die. This is the essence of a seed-limited system: saturating systems with seeds results in a higher total number of seedlings than removing mortality factors. The challenge to synthesizing available data is twofold: (1) most empirical studies do not provide sufficient data to estimate the recruitment function, and (2) alternate definitions of seed limitation are possible (and might be required, given the limitations of the available studies). This can create con- 
Table 3: Parameter values from the full Beverton-Holt function (seed, density-independent, and density-dependent limitation) and limitation and elasticity analyses for each study at ambient conditions

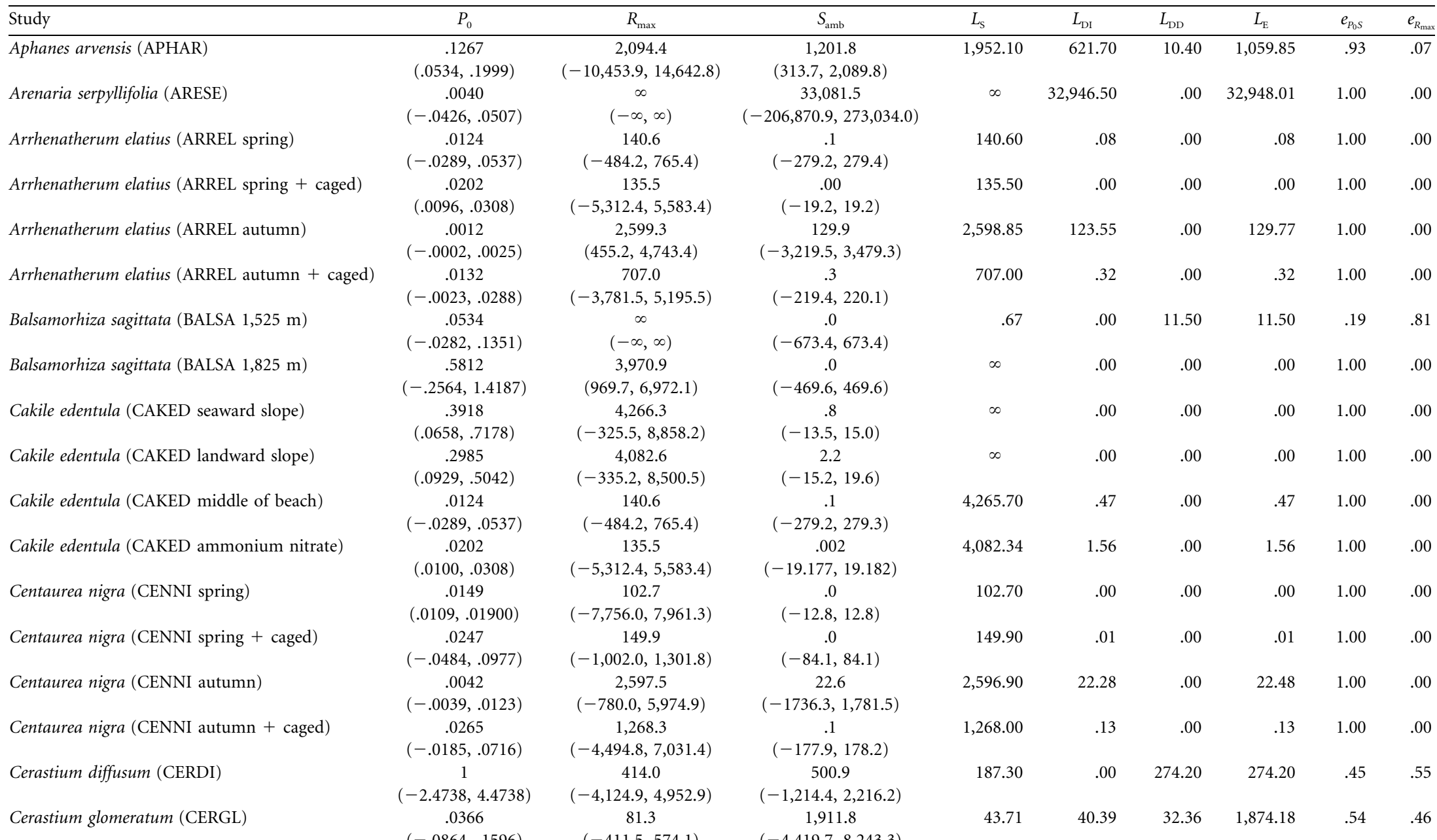


Festuca rubra (FESRU spring)

Festuca rubra (FESRU spring + caged)

Festuca rubra (FESRU autumn)

Festuca rubra (FESRU autumn + caged)

Florkea proserpinacoides (FLOPR) 1

Florkea proserpinacoides (FLOPR) 2

Lathyrus vernus (LATVE)

Myosotis ramosissima (MYORA)

Plantago coronopus (PLACO vegetation removed)

Plantago coronopus (PLACO)

Rumex acetosa (RUMAC spring)

Rumex acetosa (RUMAC spring + caged)

Rumex acetosa (RUMAC autumn)

Rumex acetosa (RUMAC autumn + caged)

Salvia lyrata (SALLY)

Saxifraga tridactilytes (SAXTR)

Veronica arvensis (VERAR)

Viola semptemloba (VIOSE road)

Viola semptemloba (VIOSE sink)

$$
\begin{array}{cc}
.0201 & 120.3 \\
(-.0782, .1184) & (-446.8,687.5) \\
.0169 & 157.4 \\
(.0120, .0218) & (-9,021.8,9,336.6) \\
.0017 & 3,249.8 \\
(.0007, .0027) & (-2,738.2,9,237.7) \\
.01721 & 1,012.3 \\
(.0007, .0338) & (-6,671.0,8,695.6) \\
.5467 & \infty \\
(-1.1335,2.2270) & (-\infty, \infty) \\
.7084 & \infty \\
(-1.4762,2.8931) & (-\infty, \infty) \\
.4369 & 4,124.8 \\
(-.3772,1.2509) & (2,365.6,5,884.0) \\
.0372 & 21,088.6 \\
(.0121, .0623) & (15,642.4,26,534.8) \\
.3700 & 3,896,517 \\
(.2180, .5220) & (3,579,029,4,214,0 \\
1 & 3.4 \\
(-77.9287,79.9287) & (-3.1,10.0) \\
.0210 & 158.4 \\
(.0163, .0258) & (-13,459.1,13,776 . \\
.1804 & 124.5 \\
(-.8028,1.1635) & (-3,495.2,3,744.2) \\
.0042 & 20,068.8 \\
(.0025, .0060) & (-3,652.8,43,790.4 \\
.0433 & 3,288.0 \\
(.0183, .0682) & (-34,429.0,41,004.9 \\
.0112 & \infty \\
(-.0152, .0375) & (-\infty, \infty) \\
1 & 66.7 \\
(-21.4557,23.4557) & (-294.8,428.2) \\
.0230 & \infty \\
(-.0778, .1239) & (-\infty, \infty) \\
.6073 & \infty \\
(.5231, .6915) & (-\infty, \infty) \\
.6049 & \infty \\
(.4088, .8010) & (-\infty, \infty) \\
& \infty
\end{array}
$$

(1)
.1
$(-160.3,160.3)$
.0
$(-16.1,16.1)$
$2,688.5$

$(-1,816.2,7,193.2)$

235.5

$(-320.1,791.1)$

.0
$(-3,583.1,3,583.1)$

.0

$(-3,595.3,3,595.3)$

.0
$(-611.9,611.9)$

$3,725.6$

$(1,104.0,6,347.2)$

824.6

$(-360.0,2,009.2)$

\begin{tabular}{|c|c|c|c|}
\hline .02 & .00 & .02 & 1.00 \\
\hline .00 & .00 & .00 & 1.00 \\
\hline $1,466.41$ & .01 & $2,683.88$ & 1.00 \\
\hline 187.06 & .02 & 231.47 & 1.00 \\
\hline .00 & .00 & .00 & 1.00 \\
\hline .00 & .00 & .00 & 1.00 \\
\hline .00 & .00 & .00 & 1.00 \\
\hline $3,028.30$ & .99 & $3,587.88$ & .99 \\
\hline $6,892.00$ & 241.00 & $7,832.91$ & .97 \\
\hline $3,811.00$ & $1,800.00$ & $8,465.31$ & .81 \\
\hline .00 & .00 & .00 & 1.00 \\
\hline .00 & .00 & .00 & 1.00 \\
\hline 956.33 & .00 & $1,004.64$ & 1.00 \\
\hline 86.42 & .01 & 88.98 & 1.00 \\
\hline 519.30 & .00 & 519.52 & 1.00 \\
\hline .00 & 59.75 & 59.75 & .40 \\
\hline $8,603.50$ & .00 & $8,603.04$ & 1.00 \\
\hline .00 & .00 & .00 & 1.00 \\
\hline .00 & .00 & .00 & 1.00 \\
\hline
\end{tabular}

14.3

$(-1,028.7,1,057.2)$

.0
$(-8.9,8.9)$

$(-8.9,8.9)$

.0
$(-3.1,3.1)$

$1,008.9$

$(-466.8,2,484.6)$

93.0

$(-76.3,262.3)$

.0
$13.3,113.3)$

99.7

$(-2,081.6,2,281.0)$ $8,805.5$

$(-23,395.1,41,006.2)$

$(-\infty, \infty)$

$(-1.6,1.6)$

.0
$(-3.7,3.7)$
120.30

$$
157.40
$$

$3,245.41$

$1,007.96$

$\infty$

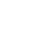

$\infty$

$\infty$

$20,952.30$

$218,742.00 \quad 6,892.00$

$31,471.00 \quad 3,811.00$

158.40

124.50

$20,065.73$

$3,283.98$

$3,896,694.90$

26.7

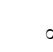

$\infty$

$3,971.00$
Note: Values in parentheses represent $95 \%$ confidence intervals. $P_{0}=$ density-independent survival (constrained between 0 and 1 ), $R_{\max }=$ maximum seedling density, $S_{\text {amb }}=$ background seed density, $L_{\mathrm{S}}=$ limitation due to seed input, $L_{\mathrm{DI}}=$ density-independent limitation, $L_{\mathrm{DD}}=$ density-dependent limitation, and $L_{\mathrm{F}}=$ establishment limitation. Elasticities are for seed supply and density-independent survival $\left(e_{P_{0} S}\right)$ and the density dependence parameter $\left(e_{R_{\max }}\right)$. 
fusion in the literature, where the match between theory and empirical studies is currently weak.

\section{Caveats}

We have argued that the study of seed limitation in plants can be facilitated by applying an analytical framework developed for reef fish (Schmitt et al. 1999). Using this approach, we have quantified the relative importance of multiple factors that contribute to the recruitment of seedlings. The dichotomy of seed-limited versus establishmentlimited plant populations is too simplistic (Clark et al. 2007); seedling recruitment is better described as a continuum along which the strength of seed or establishment limitation changes with increasing seed input (figs. 1, 2). Despite our success in applying an approach developed for fishes, there are limitations to this approach. For example, the strength of processes can change dramatically over the life of a plant, and the results we obtained for the seed-to-seedling transition may not apply to other life stages or to species with different life histories. Most of the species examined here are annuals (10 of 18 species) or fairly short-lived perennials (longevity between three and 10 years) and not tropical trees (app. A). Had we used a different endpoint (e.g., adult plants instead of seedlings), we would have obtained different results. A full picture of seed and establishment limitation requires data from the entire life cycle, but these data are rare in the literature.

The density of seeds determines where a species lies along its recruitment function, and for a single system, this is likely to vary ontogenetically (i.e., with life stage), spatially (e.g., with proximity to the adult plant), or temporally (e.g., with interseasonal and interannual variation in seed production and biotic interactions). For example, the spatial patterns of seeds and seedlings are tied to the spatial pattern of adults (i.e., dispersal of plants is more local than dispersal in reef fishes), so we expect that the magnitude of seed limitation will depend on proximity to adult plants because of both variation in seed density and the strength of density-dependent losses (Janzen 1970; HilleRisLambers et al. 2002; Morales and Carlo 2006).

Our analyses also did not distinguish between seed viability and postdispersal density-independent mortality (their effects were combined in the parameter $P_{0}$ ). We therefore searched the literature for germination data to assess how much of the losses were due to seed viability versus mortality of viable seeds. For 13 of the 18 species included in this study, mean germination rates averaged 80\% (Froud-Williams et al. 1984; Maun and LaPierre 1986; Hutchings and Russell 1989; Oakley 2004; Rahman et al. 2004; Vance 2004; Dostál 2005). Therefore, we slightly underestimated the survival at low density $\left(P_{0}\right)$ because $\sim 20 \%$ of seeds were likely already dead when they were added to experimental plots. It also means that we overestimated $A$ and $S_{\text {amb }}$ because our scale for seed density must be adjusted downward (e.g., $A^{\prime}=v A$, where $A^{\prime}$ is the true augmentation level, and $v$ is the proportion of seeds that are viable). Similarly, if species have high seed dormancy, then the actual level of augmentation will be lower than we have estimated in our approach because seeds not observed as seedlings are counted as dead even though they may still be viable (but have not yet germinated); that is, $A$ must be reduced and $P_{0}$ increased accordingly. When the effects of seed viability and dormancy are quantified and accounted for, estimates of limitation (and elasticity) may change. However, given the extreme results we obtained and the high seed viabilities for the studied species, we suspect that this bias is typically small.

The relative importance of seed limitation depends on the ambient seed rain, yet this was not reported in any of the studies. We had to estimate the combined effect of seed rain and the seed bank $\left(S_{\text {amb }}\right)$ indirectly from the recruitment data, and the resulting estimates of $S_{\text {amb }}$ were extremely variable. This is not surprising because seeds are often dispersed in clumped distributions (Clark et al. 2005). Empirical studies of seed rain (and of seed banks), in conjunction with seed augmentation experiments, will help us better assess the recruitment function, the importance of seed limitation, and the spatial variation in these processes.

\section{Applying and Extending the Framework}

Given the above framework for examining seed and establishment limitation, we now need studies that apply it. Although this could be accomplished by measuring natural seed densities and subsequent seedling establishment, seed densities may not vary enough in a single season, or where they do (with distance from parent plant), it may be difficult to distinguish the effects of seed density from the effects of differences in microsites. There also may be correlations between microsite characteristics that affect survival (or the strength of density dependence) and seed rain, which could bias estimates of the recruitment function (e.g., Wilson and Osenberg 2002; Shima and Osenberg 2003). Therefore, we advocate improving seed augmentation experiments to learn more about the processes that determine recruitment. Estimation of the functional form will require many more levels of seed augmentation than has been used in past experiments. Indeed, only 26\% (11 of 43) of published articles on seed augmentation experiments include more than one level of seed augmentation (Clark et al. 2007). Obtaining accurate estimates of density-independent mortality will likely require manipulation of seed densities at several low densities, which may require reduction in seed input relative to ambient seed rain or 
the seed bank. This type of treatment is rarely considered. On the other end of the curve, it is critical to include several high-augmentation densities (even if such densities are only rarely achieved in the field) to facilitate estimation of the saturation density (Schmitt et al. 1999). Adding seeds at a minimum of five levels will permit parameter estimation for three-parameter models and verification of model fits with goodness-of-fit tests, but we recommend more than this minimum.

With larger sample sizes, the power to detect more complex recruitment functions will be enhanced. In preliminary analyses, we tested four different recruitment functions (linear, power, Beverton-Holt, and Ricker) against one another, determining the Beverton-Holt model to be the best-fitting model that enabled the detection of density dependence. However, in two of 37 studies, the humpshaped Ricker model was the best-fitting model, demonstrating that density dependence can be sufficiently strong to lead to overcompensation. The Ricker, BevertonHolt, and power functions include only negative effects of density (but see Myers et al. 1995 for a modified version of the Beverton-Holt function that incorporates positive density dependence). In contrast, Blundell and Peart (2004) found that early seedling recruitment in a tropical tree population was positively density dependent, probably because of predator satiation. In such cases, we will need to develop models that incorporate both positive and negative effects of density, whose relative importance changes as a function of seed density. The resulting recruitment functions will be more complex than those we have dealt with here.

Importantly, densities of seeds applied in augmentation studies should be based on the natural seed rain and seed bank. Without knowing background seed density, it is difficult to determine where on the recruitment function the ambient system lies. Seed viability and dormancy tests also should be conducted. Both viability and dormancy can vary greatly, depending on the year and season that seeds are collected (Thompson and Grime 1979; Thompson et al. 1997; Krinke et al. 2005), and can affect estimates of density-independent mortality. In addition, seed augmentation experiments conducted in different seasons or habitats or under different treatments (e.g., caging or vegetation removal) can elucidate the conditions and species characteristics that explain differences in the recruitment function and patterns of seed and establishment limitation (Edwards and Crawley 1999).

Studies could quantify effects across different environments and reveal how seed input and the recruitment function vary in space and time (e.g., Wilson and Osenberg 2002; Shima and Osenberg 2003). For example, the density of different cohorts of the same species and/or the density of heterospecific competitors could influence recruitment dynamics. Comparative studies could then explore how the intensity of density independence, density dependence, and seed limitation varies among species that differ in lifehistory traits (e.g., seed size) and occupy different habitats or environmental conditions. Seedling establishment is an important determinant of plant population dynamics and community species richness (Tilman 1993; Weiher and Keddy 1995). Therefore, by quantifying the factors that cause species to be rare or abundant, we move another step closer to understanding the determinants of population and community organization.

\section{Acknowledgments}

This work was initiated as part of the Quantitative Methods and Ecological Inference course at the University of Florida. We would like to thank D. Blondel, N. Brennan, H. Klug, J. Martin, M. McCoy, and M. Mota for assistance with the initial literature search and data extraction and N. Seavy for helpful discussion in the development of the article. This manuscript could not have been written without the cooperation and generosity of authors who sent us data or information about their data sets, including $\mathrm{L}$. Amsberry, M. J. Crawley, G. R. Edwards, P. Manning, P. D. Putwain, N. R. Webb, and A. Winn. We also thank T. Okuyama and M. Roy for assistance with analyses and A. Moles, D. Peart, and two anonymous reviewers for helpful comments on the article. Financial support was provided by National Science Foundation (NSF) grant OCE0242312 to C.W.O., C. St. Mary, and B.M.B., NSF grant DEB-9815834 to D.J.L., a University of Florida Presidential fellowship to J.R.P., a School of Natural Resources and Environment alumni fellowship to C.J.C., and Environmental Protection Agency Science to Achieve Results (STAR) fellowships (91630801-0 and 91643301-0, respectively) to C.J.C. and J.R.P.

\section{Literature Cited}

Amsberry, L. 2003. Dispersers and herbivores: positive and negative effects of consumers on plants. MS thesis. University of Montana, Missoula.

Augspurger, C. K., and K. Kitajima. 1992. Experimental studies of seedling recruitment from contrasting seed distributions. Ecology 73:1270-1284.

Beverton, R. J. H., and S. J. Holt. 1957. On the dynamics of exploited fish populations. Chapman \& Hall, London.

Blundell, A. G., and D. R. Peart. 2004. Density-dependent population dynamics of a dominant rain forest canopy tree. Ecology 85:704715.

Caley, M. J., M. H. Carr, M. A. Hixon, T. P. Hughes, G. P. Jones, and B. A. Menge. 1996. Recruitment and the local dynamics of open marine populations. Annual Review of Ecology and Systematics 27:477-500.

Caswell, H. 2001. Matrix population models: construction, analysis, and interpretation. Sinauer, Sunderland, MA. 
Clark, C. J., J. R. Poulsen, B. W. Bolker, E. F. Connor, and V. T. Parker. 2005. Comparative seed shadows of bird-, monkey-, and wind-dispersed tree species in a central African tropical forest. Ecology 86:2684-2694.

Clark, C. J., J. R. Poulsen, D. J. Levey, and C. W. Osenberg. 2007. Are plant populations seed limited? a critique and meta-analysis of seed addition experiments. American Naturalist 170:128-142.

Clark, J. S., E. Macklin, and L. Wood. 1998. Stages and spatial scales of recruitment limitation in southern Appalachian forests. Ecological Monographs 68:213-235.

Crawley, M. J. 1990. The population dynamics of plants. Pages 318 in M. P. Hassell and R. M. May, eds. Population regulation and dynamics. Royal Society, London.

Dalling, J. W., H. C. Muller-Landau, S. J. Wright, and S. P. Hubbell. 2002. Role of dispersal in the recruitment limitation of Neotropical pioneer species. Journal of Ecology 90:714-727.

Doherty, P. J. 2002. Variable replenishment and the dynamics of reef fish populations. Pages 327-355 in P. F. Sale, ed. Coral reef fishes: dynamics and diversity in a complex ecosystem. Academic Press, San Diego, CA.

Dostál, P. 2005. Is the population turnover of patchy-distributed annuals determined by dormancy dynamics or dispersal processes? Ecography 28:745-756.

Edwards, G. R., and M. J. Crawley. 1999. Rodent seed predation and seedling recruitment in mesic grassland. Oecologia (Berlin) 118: 288-296.

Ehrlén, J., and O. Eriksson. 1996. Seedling recruitment in the perennial herb Lathyrus vernus. Flora 191:377-383.

Eriksson, O., and J. Ehrlén. 1992. Seed and microsite limitation of recruitment in plant populations. Oecologia (Berlin) 91:360-364.

Froud-Williams, R. J., D. S. H. Drennan, and R. J. Chancellor. 1984. The influence of burial and dry storage upon cyclic changes in dormancy, germination, and response to light in seeds of various arable weeds. New Phytologist 96:473-481.

Gaines, S., and J. Roughgarden. 1985. Larval settlement rate: a leading determinant of structure in an ecological community of the marine intertidal zone. Proceedings of the National Academy of Sciences of the USA 82:3707-3711.

Gurevitch, J., and L. V. Hedges. 1999. Statistical issues in ecological meta-analyses. Ecology 80:1142-1149.

Harms, K. E., S. J. Wright, O. Calderon, A. Hernandez, and E. A. Herre. 2000. Pervasive density-dependent recruitment enhances seedling diversity in a tropical forest. Nature 404:493-495.

Hedges, L. V., and I. Olkin. 1985. Statistical methods for metaanalysis. Academic Press, San Diego, CA.

HilleRisLambers, J., J. S. Clark, and B. Beckage. 2002. Densitydependent mortality and the latitudinal gradient in species diversity. Nature 417:732-735.

Hixon, M. A., and M. H. Carr. 1997. Synergistic predation, density dependence, and population regulation in a marine fish. Science 277:946-949.

Hutchings, M. J., and P. J. Russell. 1989. The seed regeneration dynamics of an emergent salt marsh. Journal of Ecology 77:615-637.

Janzen, D. H. 1970. Herbivores and the number of tree species in tropical forests. American Naturalist 104:501-528.

Keddy, P. A. 1981. Experimental demography of the sand-dune annual, Cakile edentula, growing along an environmental gradient in Nova Scotia. Journal of Ecology 69:615-630.

Krinke, L., L. Moravcova, P. Pysek, V. Jarosik, J. Pergl, and I. Perglova.
2005. Seed bank of an invasive alien, Heracleum mantegazzianum, and its seasonal dynamics. Seed Science Research 15:239-248.

Levine, M. J., and D. J. Murrell. 2003. The community-level consequences of seed dispersal patterns. Annual Review of Ecology, Evolution, and Systematics. 34:549-574.

Maun, M. A., and J. LaPierre. 1986. Effects of burial by sand on seed germination and seedling emergence of four dune species. American Journal of Botany 73:450-455.

Morales, J. M., and T. A. Carlo. 2006. The effects of plant distribution and frugivore density on the scale and shape of dispersal kernels. Ecology 86:1489-1496.

Muller-Landau, H. C., S. J. Wright, O. Calderon, S. P. Hubbell, and R. B. Foster. 2002. Assessing recruitment limitation: concepts, methods and case-studies from a tropical forest. Pages 35-53 in D. J. Levey, W. R. Silva, and M. Galetti, eds. Seed dispersal and frugivory: ecology, evolution and conservation. CAB International, Wallingford, UK.

Myers, R. A., N. J. Barrowman, J. A. Hutchings, and A. A. Rosenberg. 1995. Population dynamics of exploited fish stocks at low population levels. Science 269:1106-1108.

Oakley, C. J. 2004. Inbreeding depression and mating system evolution in the perennial herb Viola septemloba and the evolutionary maintenance of cleistogamy. MS thesis. Florida State University, Tallahassee.

Osenberg, C. W., and G. G. Mittelbach. 1996. The relative importance of resource limitation and predator limitation in food chains. Pages 134-148 in G. A. Polis and K. O. Winemiller, eds. Food webs: integration of patterns and dynamics. Chapman \& Hall, New York.

Osenberg, C. W., O. Sarnelle, S. D. Cooper, and R. D. Holt. 1999. Resolving ecological questions through meta-analysis: goals, metrics, and models. Ecology 80:1105-1117.

Osenberg, C. W., C. M. St. Mary, R. J. Schmitt, S. J. Holbrook, P. Chesson, and B. Byrne. 2002. Rethinking ecological inference: density dependence in reef fish. Ecology Letters 5:715-721.

Packer, A., and K. Clay. 2000. Soil pathogens and spatial patterns of seedling mortality in a temperature tree. Nature 404:278-281.

R Development Core Team. 2005. R: a language and environment for statistical computing. Foundation for Statistical Computing, Vienna. http://www.R-project.org.

Rahman, A., T. K. James, J. M. Mellsop, and N. Grbavac. 2004. Effects of cultivation methods on weed seed distribution and seedling emergence. New Zealand Plant Protection 57:281-285.

Rosenberg, M. S., D. C. Adams, and J. Gurevitch. 2000. MetaWin: statistical software for meta-analysis. Version 2.0. Sinauer, Sunderland, MA.

Schmitt, R. J., S. J. Holbrook, and C. W. Osenberg. 1999. Quantifying the effects of multiple processes on local abundance: a cohort approach for open populations. Ecology Letters 2:294-303.

Shaw, R. G., and J. Antonovics. 1986. Density-dependence in Salvia lyrata, a herbaceous perennial: the effects of experimental alteration of seed densities. Journal of Ecology 74:797-813.

Shima, J. S., and C. W. Osenberg. 2003. Cryptic density dependence: effects of covariation between density and site quality in reef fish. Ecology 84:45-52.

Siemann, E., and W. E. Rogers. 2003. Herbivory, disease, recruitment limitation, and success of alien and native tree species. Ecology 84:1489-1505.

Smith, B. H. 1983. Demography of Floerkea proserpinacoides, a forestfloor annual. III. Dynamics of seed and seedling populations. Journal of Ecology 71:413-425. 
Thompson, K., and J. P. Grime. 1979. Seasonal variation in the seed banks of herbaceous species in ten contrasting habitats. Journal of Ecology 67:893-921.

Thompson, K., J. P. Bakker, and R. M. Bekker. 1997. The soil seed banks of north west Europe: methodology, density, and longevity. Cambridge University Press, Cambridge.

Tilman, D. 1993. Species richness of experimental productivity gradients: how important is colonization limitation? Ecology 74:2179_ 2191.

Turnbull, L. A., M. Rees, and M. J. Crawley. 1999. Seed mass and the competition/colonization trade-off: a sowing experiment. Journal of Ecology 87:899-912.

Turnbull, L. A., M. J. Crawley, and M. Rees. 2000. Are plant populations limited? a review of seed sowing experiments. Oikos 88: 225-238.

Vance, N. 2004. Evaluating native plant seeds for restoration/rehabilitation: Eyerly fire complex, Deschutes National Forest. USDA Forest Service Pacific Northwest Research Station, Corvallis, OR.
Venables, V., and B. Ripley. 2002. Modern applied statistics with S. 4 th ed. Springer, New York.

Waite, S., and J. Hutchings. 1979. A comparative study of establishment of Plantago coronopus: from seeds sown randomly and in clumps. New Phytologist 82:575-583.

Webb, C. O., and D. R. Peart. 1999. Seedling density dependence promotes coexistence of Bornean rain forest trees. Ecology 20: 2006-2017.

Weiher, E., and P. A. Keddy. 1995. Assembly rules, null models, and trait dispersion: new questions from old patterns. Oikos 74:159164.

Wilson, J., and C. W. Osenberg. 2002. Experimental and observational patterns of density-dependent settlement and survival in the marine fish Gobiosoma. Oecologia (Berlin) 130:205-215.

Associate Editor: Catherine A. Pfister Editor: Donald L. DeAngelis 


\section{Appendix A from J. Poulsen et al., 'Plants as Reef Fish: Fitting the Functional Form of Seedling Recruitment"}

(Am. Nat., vol. 170, no. 2, p. 167)

Table A1

Species Included in the Analysis

\begin{tabular}{|c|c|c|c|c|c|c|c|}
\hline Species & Plot size $\left(\mathrm{m}^{2}\right)$ & Seed augmentation levels & $\begin{array}{l}\text { Duration } \\
\text { (days) }\end{array}$ & $\begin{array}{l}\text { Life } \\
\text { form }^{\mathrm{a}}\end{array}$ & Habitat & Treatments & Reference \\
\hline Aphanes arvensis & .1 & $0,100,500,2,000$ & 365 & $\mathrm{AG}$ & Grassland & No treatment & Turnbull et al. 1999 \\
\hline Arenaria serpyllifolia & .1 & $0,100,500,2,000$ & 365 & $\mathrm{AH}$ & Grassland & No treatment & Turnbull et al. 1999 \\
\hline Arrhenatherum elatius & .25 & $0,4,000,40,000,200,000$ & 450 & PG & Grassland & Caged and uncaged, spring and autumn & Edwards and Crawley 1999 \\
\hline Balsamorhiza sagittata & 1.5 & $0,78,150,300,600$ & 365 & PH & Grassland & Elevations of 1,525 and $1,825 \mathrm{~m}$ & Amsberry 2003 \\
\hline Cakile edentula & $\begin{array}{c}.2,4, .4, .4, .16, .08 \\
.08, .08\end{array}$ & $\begin{array}{l}0,100,50,100,100,100 \\
\quad 200,400\end{array}$ & 165 & $\mathrm{AH}$ & Intertidal & $\begin{array}{l}\text { Seaward slope of beach, landward slope of } \\
\text { beach, middle of beach side of dune, and } \\
\text { addition of ammonium nitrate }\end{array}$ & Keddy 1981 \\
\hline Centaurea nigra & .25 & $0,4,000,40,000,200,000$ & 450 & $\mathrm{PH}$ & Grassland & Caged and uncaged, spring and autumn & Edwards and Crawley 1999 \\
\hline Cerastium diffusum & .1 & $0,100,500,2,000$ & 365 & $\mathrm{AH}$ & Grassland & No treatment & Turnbull et al. 1999 \\
\hline Cerastium glomeratum & .1 & $0,100,500,2,000$ & 365 & $\mathrm{AH}$ & Grassland & No treatment & Turnbull et al. 1999 \\
\hline Festuca rubra & .25 & $0,4,000,40,000,200,000$ & 450 & PG & Grassland & Caged and uncaged, spring and autumn & Edwards and Crawley 1999 \\
\hline Florkea proserpinacoides & .0675 & $75,150,300,450$ & 365 & $\mathrm{AH}$ & Forest & No treatment & Smith 1983 \\
\hline Lathyrus vernus & $\begin{array}{l}.99,3.96, .99, .2475 \\
.0616, .0154\end{array}$ & 550 & 1,460 & PH & Forest & No treatment & Ehrlén and Eriksson 1996 \\
\hline Myosotis ramosissima & .1 & $0,100,500,2,000$ & 365 & $\mathrm{AH}$ & Grassland & No treatment & Turnbull et al. 1999 \\
\hline Plantago coronopus & .004 & $0,200,400,800$ & 56 & $\mathrm{AH}$ & Intertidal & Vegetation removed and vegetation intact & Waite and Hutchings 1979 \\
\hline Rumex acetosa & .25 & $0,4,000,40,000,200,000$ & 450 & $\mathrm{PH}$ & Grassland & Caged and uncaged, spring and autumn & Edwards and Crawley 1999 \\
\hline Salvia lyrata & $\begin{array}{c}.08, .04, .04, .04, .04 \\
.04, .04, .04, .04\end{array}$ & $\begin{array}{l}0,120,240,480,960 \\
1,920,2,880,3,840 \\
5,760\end{array}$ & 365 & PH & Grassland & No treatment & Shaw and Antonovics 1986 \\
\hline Saxifraga tridactilytes & .1 & $0,100,500,2,000$ & 365 & $\mathrm{AH}$ & Grassland & No treatment & Turnbull et al. 1999 \\
\hline Veronica arvensis & .1 & $0,100,500,2,000$ & 365 & $\mathrm{AH}$ & Grassland & No treatment & Turnbull et al. 1999 \\
\hline Viola semptemloba & $.5625, .25, .1875, .125$ & $180,160,240,240$ & 120 & $\mathrm{PH}$ & Forest & Road and sink & A. Winn, unpublished data \\
\hline
\end{tabular}

Note: The average maximum life span of the perennial species is between 3 and 10 years, with the exception of Lathyrus vernus, which can live up to nearly 60 years.

${ }^{a} \mathrm{AG}=$ annual grass, $\mathrm{AH}=$ annual herb, $\mathrm{PG}=$ perennial grass, $\mathrm{PH}=$ perennial herb. 


\section{Appendix B from J. Poulsen et al., "Plants as Reef Fish: Fitting the Functional Form of Seedling Recruitment"}

(Am. Nat., vol. 170, no. 2, p. 167)

\section{Candidate Recruitment Function Model Fits}

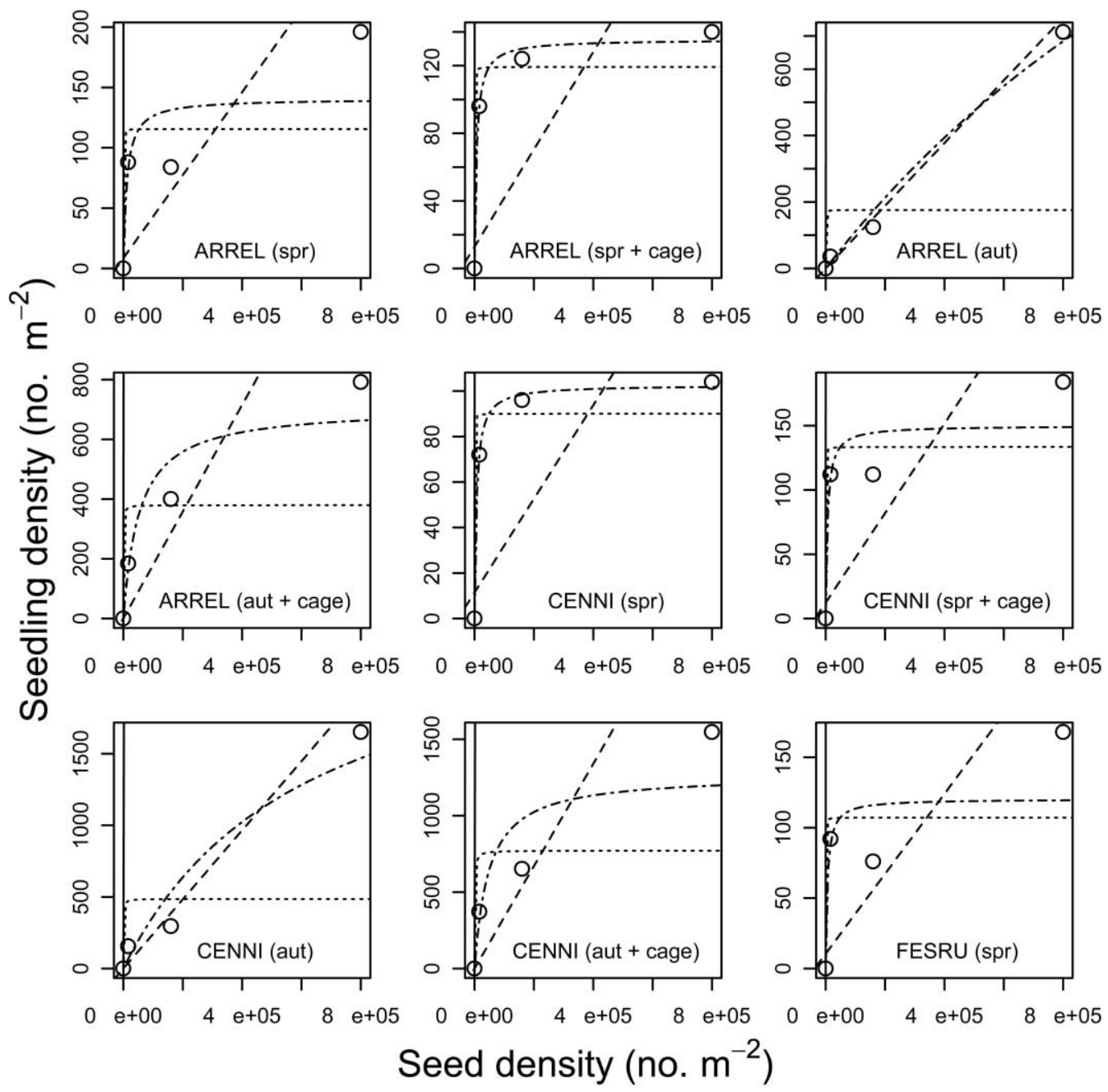

Figure B1: Fit of four candidate recruitment function models to seed augmentation data (density of seedlings per square meter vs. density of seeds added to a plot) for nine of the 37 studies (Arrhenatherum elatius, Centaurea nigra, Festuca rubra). The solid line represents the seed-limitation-only model (fitting $S_{\text {amb }}$ ), the dashed line represents the no-density-dependent-limitation model (fitting $P_{0}$ and $S_{\text {amb }}$ ), the dotted line represents the nodensity-independent-limitation model (fitting $R_{\max }$ and $S_{\text {amb }}$ ), and the dash-dotted line represents the seed-, densityindependent-, and density-dependent-limitation model (fitting $P_{0}, R_{\max }$, and $S_{\text {amb }}$ ). Codes at the bottom of the plots are the first three letters of the genus name and first two letters of the species name, with the type of treatment 
App. B from J. Poulsen et al., "Plants as Reef Fish"

abbreviated in parentheses. See table 2 for a full description of the species name and disturbance and/or treatment.

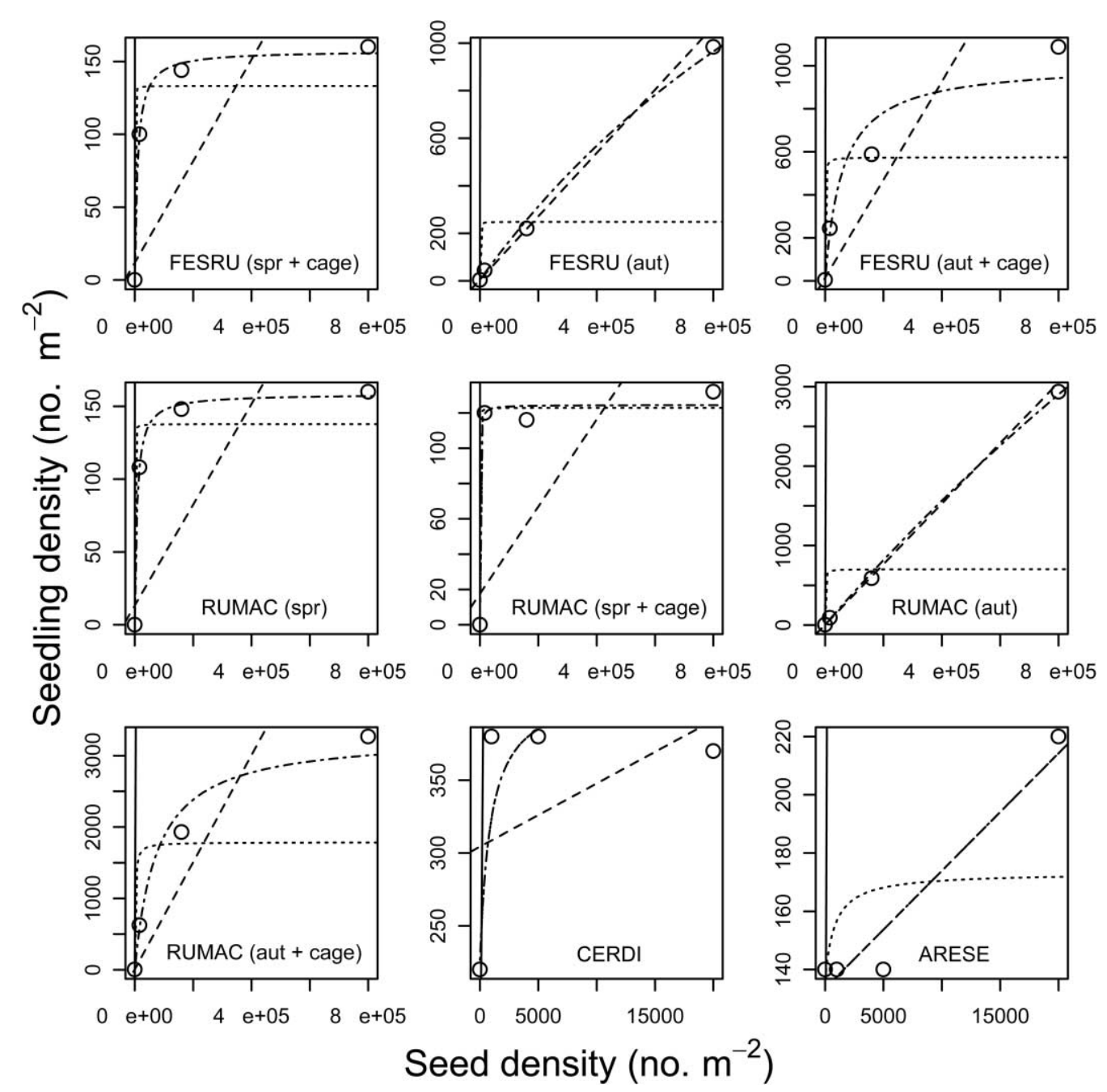

Figure B2: Fit of four candidate recruitment function models to seed augmentation data for nine of the 37 studies (Festuca rubra, Rumex acetosa, Cerastium diffusum, Arenaria serpyllifolia). See figure B1 for details. 
App. B from J. Poulsen et al., "Plants as Reef Fish"
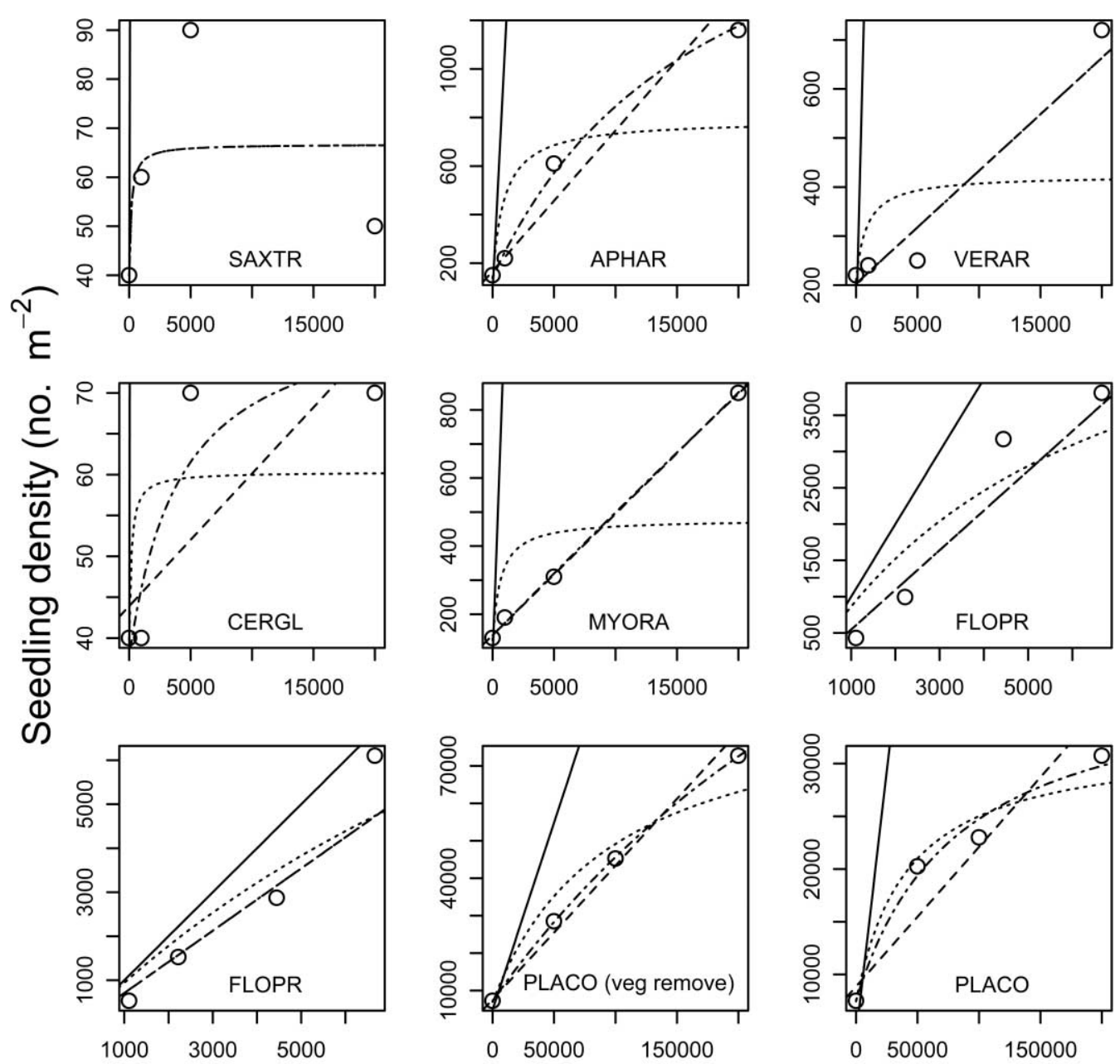

Seed density (no. $\mathrm{m}^{-2}$ )

Figure B3: Fit of four candidate recruitment function models to seed augmentation data for nine of the 37 studies (Saxifraga tridactilytes, Aphanes arvensis, Veronica arvensis, Cerastium glomeratum, Myosotis ramosissima, Florkea proserpinacoides, Plantago coronopus). See figure B1 for details. 

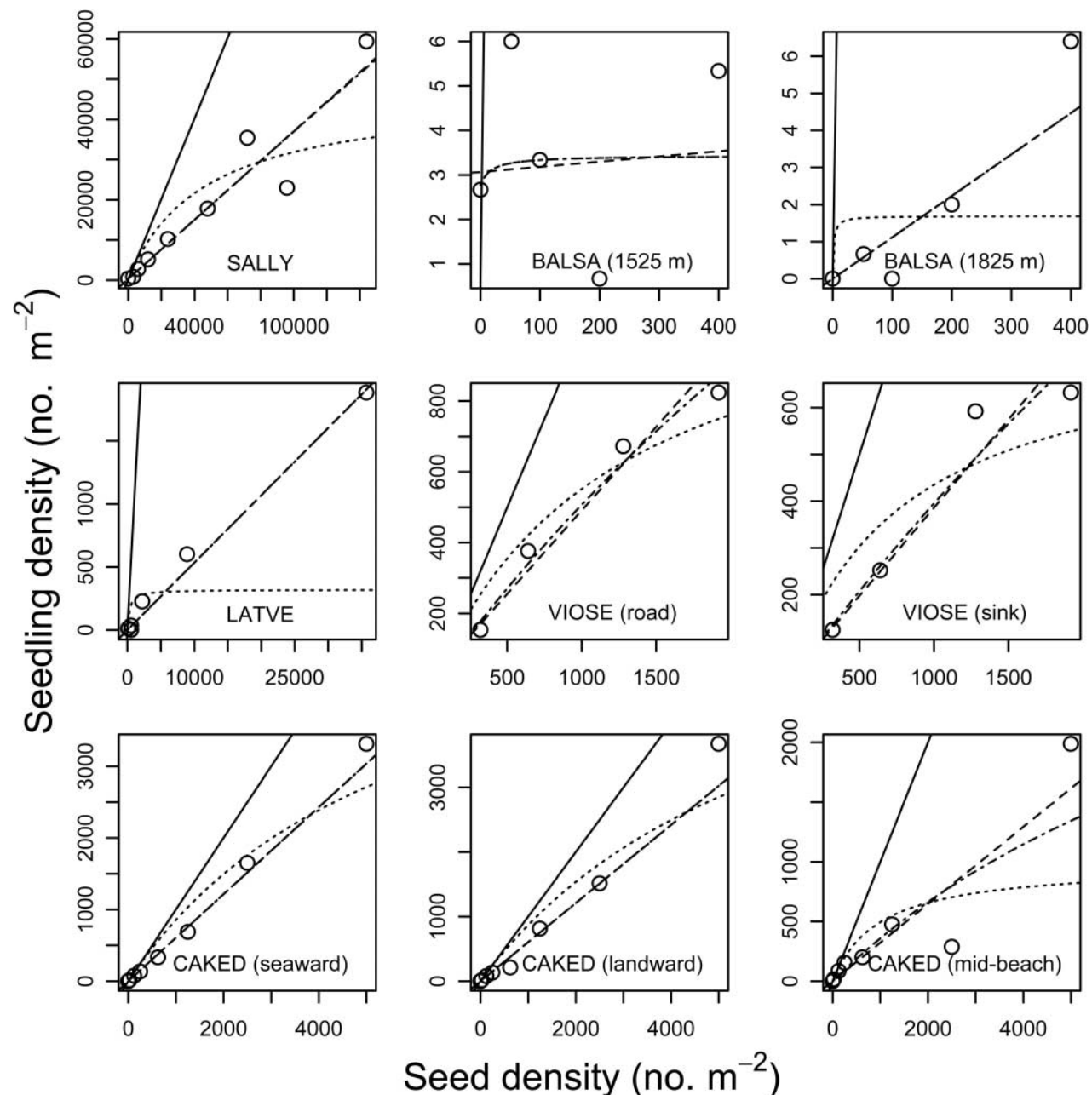

Figure B4: Fit of four candidate recruitment function models to seed augmentation data for nine of the 37 studies (Salvia lyrata, Balsamorhiza sagittata, Lathyrus vernus, Viola semptemloba, Cakile edentula). See figure B1 for details.

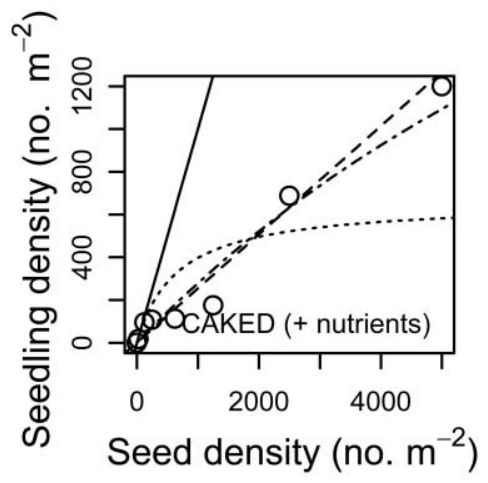

Figure B5: Fit of four candidate recruitment function models to seed augmentation data for Cakile edentula with the ammonium nitrate treatment. See figure B1 for details. 